\title{
Caracterização morfológica, física e química de solos da bacia hidrográfica do médio curso do rio Teles Pires, no Município de Alta Floresta - MT
}

Morphological, physical and chemical characterization of soils in the middle high stroke of the Teles Pires river basin, in the City of Alta Floresta - MT

Caracterización morfológica, física y química de suelos de la cuenca hidrográfica del curso medio del río Teles Pires, en el Municipio de Alta Floresta - MT

Recebido: 12/07/2021 | Revisado: 18/07/2021 | Aceito: 20/07/2021 | Publicado: 28/07/2021

Ademilso Sampaio de Oliveira ORCID: https://orcid.org/0000-0003-0816-9559 Universidade do Estado do Mato Grosso, Brasil E-mail: ademilsosampaio@gmail.com

Maria Aparecida Pereira Pierangeli ORCID: https://orcid.org/0000-0001-6453-080X Universidade do Estado do Mato Grosso, Brasil E-mail: mappierangeli@gmail.com Juberto Babilônia de Sousa ORCID: https://orcid.org/0000-0002-7752-1416 Universidade do Estado do Mato Grosso, Brasil E-mail: juberto.sousa@ cas.ifmt.edu.br

Humbelina Silva Siqueira Lopes ORCID: https://orcid.org/0000-0002-8911-5255 Universidade do Estado de Santa Catarina, Brasil E-mail: humbelinas@hotmail.com

Carla Galbiati

ORCID: https://orcid.org/0000-0001-5442-1562 Universidade do Estado do Mato Grosso, Brasil E-mail: carla@unemat.br

Célia Alves de Souza

ORCID: https://orcid.org/0000-0002-9068-9328 Universidade do Estado do Mato Grosso, Brasil E-mail: celiaalvesgeo@globo.com

Wesley Vicente Claudino

ORCID: https://orcid.org/0000-0002-4074-1706 Universidade do Estado do Mato Grosso, Brasil E-mail: wesleyherbam@gmail.com

\begin{abstract}
Resumo
O objetivo deste estudo foi identificar as feições morfológicas e pedogenética dos solos e suas características químicas e físicas na bacia hidrográfica do Médio Curso do Rio Teles Pires (BHMTP). Para isso, foram estudados seis perfis de solo, em trincheiras, ao longo das margens direita e esquerda do Rio Teles Pires, localizados nas Fazenda Encanto da Natureza, Fazenda São José, Rio Teles Pires, Fazenda Estrada do Espanhol, Comunidade Bonfim e Fazenda Vaca Branca. Foram feitas em cada horizonte as análises morfológicas descritivas e posteriormente coletados solos para análises físicas e químicas. Por meio da interpretação das avaliações morfológicas dos perfis, associada aos resultados de análises físico-químicas dos solos, os solos foram classificados até o quarto nível categórico, sendo dois ARGISSOLO VERMELHO-AMARELO Distrófico típico (PVAd), localizados sobre a margem esquerda do rio; dois Latossolos, LATOSSOLO VERMELHO Eutrófico típico (LVe) e LATOSSOLO VERMELHO-AMARELO Distrófico típico (LVAd) localizados à direita do rio; um GLEISSOLO HÁPLICO Tb Distrófico plintossólico (GXbd) localizado à esquerda e um CAMBISSOLO HÁPLICO Tb Distrófico (CXbd) à direita do rio Teles Pires. Em geral, os solos apresentaram texturas médias em todos os perfis. A saturação por $\mathrm{Al}^{3+}$ foi elevada na maioria dos horizontes, refletindo os baixos valores de $\mathrm{pH}$ e menores teores de $\mathrm{Ca}^{2+}, \mathrm{Mg}^{2+}, \mathrm{K}^{+}$e, consequentemente, menores saturação por bases, exceto o LVe, cuja CTC foi alta. Todos os solos apresentaram média capacidade de troca de cátions (CTC), fato que reflete a mineralogia típica de solos intemperizados.
\end{abstract}

Palavras-chave: SiBCS; Bioma amazônico; Pedologia. 
The aim of this study was to identify the morphological and pedogenetic features of the soils and their chemical and physical characteristics in the hydrographic basin of the Middle Course of Rio Teles Pires (BHMTP). For this, six soil profiles were studied, in trenches, along the right and left banks of the Teles Pires River, located at the Encanto da Natureza Farm, São José Farm, Teles Pires River, Estrada do Espanhol Farm, Bonfim Community and Vaca Farm White. Descriptive morphological analyzes were carried out on each horizon and subsequently soil was collected for physical and chemical analysis. Through the interpretation of the morphological evaluations of the profiles, associated with the results of physical-chemical analyzes of the soils, it is possible to classified up to the fourth categorical level, two ARGISSOLO VERMELHO-AMARELO Distrófico típico (PVAd), located on the left bank of the river, two Oxisols, LATOSSOLO VERMELHO Eutrófico típico (LVe) e LATOSSOLO VERMELHO-AMARELO Distrófico típico (LVAd) located on the right side of the river, a GLEISSOLO HÁPLICO Tb Distrófico plintossólico (GXbd) located on the left and a CAMBISSOLO HÁPLICO Tb Distrófico (CXbd) Teles Pires River.. In general the soils showed medium textures in all profiles. Saturation by $\mathrm{Al}^{3+}$, it was high in most horizons, reflecting low $\mathrm{pH}$ values and lower levels of $\mathrm{Ca}^{2+}, \mathrm{Mg}^{2+}, \mathrm{K}^{+}$and, consequently, lower base saturation, except LVe. Except for LVe, whose CTC was high, all soils showed average cation exchange capacity (CTC), a fact that reflects the typical mineralogy of weathered soils.

Keywords: SiBCS; Amazon biome; Pedology.

\section{Resumen}

El objetivo de este estudio fue identificar las características morfológicas y pedogenéticas de los suelos y sus características químicas y físicas en la cuenca hidrográfica del curso medio del río Teles Pires (BHMTP). Para ello, se estudiaron seis perfiles de suelo, en trincheras, a lo largo de las márgenes derecha e izquierda del río Teles Pires, ubicado en la Fazenda Encanto da Natureza, Fazenda São José, Río Teles Pires, Fazenda Estrada do Espanhol, Comunidade Bonfim y Fazenda. Vaca White. En cada horizonte se realizaron análisis morfológicos descriptivos y posteriormente se recolectaron suelos para análisis físicos y químicos. A través de la interpretación de las evaluaciones morfológicas de los perfiles, asociadas a los resultados de los análisis físico-químicos de los suelos, es posible clasificar hasta el cuarto nivel categórico, con dos ARGISSOLO VERMELHO-AMARELO Distrófico típico (PVAd), ubicado en el margen izquierdo de Rio; dos Latosoles, LATOSSOLO VERMELHO Eutrófico típico (LVe) y LATOSSOLO VERMELHO-AMARELO Distrófico típico (LVAd) ubicados a la derecha del río; un GLEISSOLO HÁPLICO Tb Distrófico plintossólico (GXbd) ubicado a la izquierda y un CAMBISSOLO HÁPLICO Tb Distrófico (CXbd) a la derecha del río Teles Pires. En general, los suelos presentaron texturas medias en todos los perfiles. La saturación de $\mathrm{Al}^{3+}$ es alta en la mayoría de los horizontes, reflejando valores de $\mathrm{pH}$ bajos y contenidos más bajos de $\mathrm{Ca}^{2+}, \mathrm{Mg}^{2+}, \mathrm{K}^{+} \mathrm{y}$, en consecuencia, una menor saturación de bases, a excepción de LVe, cuyo CTC fue alto. Todos los suelos tenían una capacidad de intercambio catiónico (CTC) media, hecho que refleja la mineralogía típica de los suelos meteorizados.

Palabras clave: SiBCS, Bioma amazónico, Pedología.

\section{Introdução}

Muito se tem discutido a respeito da ocupação da região amazônica, em que os impactos ambientais têm se tornado assunto de extrema importância no cenário mundial atual, devido às queimadas, aquecimento global, exploração de minérios, instalação de usinas hidrelétricas, uso do solo por sistemas agrícolas e a exploração vegetal.

Apesar de vasta literatura existente sobre o meio ambiente amazônico, há necessidade de se ampliar esses conhecimentos para uma melhor compreensão dos ecossistemas amazônicos, especialmente seus solos, suas inter-relações e adaptações, em resposta às intervenções humanas (Schaefer et al., 2017).

O solo desempenha importantes funções relacionadas aos serviços ecossistêmicos, sendo diretamente conectado à segurança hídrica, alimentar e energética, e às mudanças climáticas (Adhikari et al., 2016). Quesada et al. (2020) verificaram em seus estudos que as variações nas concentrações de orgânico em solos da Floresta Amazônica são explicados pelas propriedades químicas e físicas do solo. No entanto, estudos realizados na região amazônica revelam a fragilidade e a importância desse ecossistema, diversos autores vêm discutindo o uso e a ocupação dos solos amazônicos, estudos esses sobre o comportamento dos solos no que se refere aos sistemas de cultivos (Colodel et al., 2018; Oliveira et al, 2016; Damaceno \& Lobato, 2015; Camargo et al., 2010; Oliveira, 2006), especialmente acerca da conversão de ecossistemas naturais para sistemas agrícolas ou pecuários, características morfológicas, químicas e físicas dos solos.

Malheiro, Higuchi \& Santos (2009), analisando a estrutura da floresta tropical úmida do município de Alta Floresta, em Mato Grosso, explicam que a caracterização da região amazônica é muito importante para definir a diversidade 
vegetacional, permitindo, dessa maneira, saber quais são as espécies que compõem tais áreas e de que modo elas estão distribuídas num estrato arbóreo.

A qualidade de um solo é definida por meio da interação entre atributos químicos, físicos e biológicos, que, por sua vez, são fundamentais para avaliar os impactos sofridos pelo solo em decorrência das atividades agropecuárias (Colodel et al., 2018). Segundo os mesmos autores, ao estudarem os atributos físicos e biológicos de um Argissolo Vermelho-Amarelo na região de Alta Floresta, sobre diferentes sistemas de uso e manejo, chegaram às conclusões que todos os sistemas avaliados apresentaram perdas nas qualidades físicas do solo em relação ao sistema nativo.

Oliveira, Pierangeli \& Sousa (2019), estudando as características do meio físico da Bacia Hidrográfica do Médio Curso do Rio Teles Pires (BHMTP), no município de Alta Floresta, Mato Grosso, concluíram que, em consequência das boas características edáficas da região, grande parte da área da bacia já fora transformada em pastagens ou estão sob vegetação natural sob regeneração e, assim, a vegetação nativa ainda ocupa boa parte da área, porém está sendo gradativamente substituída pelas lavouras.

Lange et al. (2019), mensurando os impactos nas propriedades químicas e físicas em um Latossolo VermelhoAmarelo cultivado com pastagem por 10 e 20 anos sem correções em comparação à condição de floresta, explicam que a conversão do uso do solo de floresta para pastagens, num período de 20 anos, resulta em redução do pH, dos teores de fósforo, potássio, cálcio, magnésio, saturação por bases e capacidade de troca catiônica.

Mendes et al. (2017) estudaram os solos e relações genéticas entre os solos e a vegetação das campinaranas em geoambientes amazônicos no rio Negro e concluíram que a vegetação e sua variação no espaço se mostraram importantes indicadores da transformação da paisagem.

Ao estudar as características morfológicas dos solos e sua organização no corte vertical e horizontal do terreno, ou seja, perfil do solo, estabelece-se a relação dos fatores de sua formação com a paisagem (vegetação, solo, água e relevo) em uma condição de tempo (Campos, 2012; Santos et al., 2015; Lepsch, 2016; Santos et al., 2018; Pereira et al., 2019). A análise das informações morfológicas possibilita uma interpretação da dinâmica pedológica do ambiente, podendo recomendar forma mais adequada de uso da terra.

Dessa forma, objetivou-se, neste estudo, identificar as feições morfológicas dos solos e suas características químicas e físicas e pedogenéticas na bacia hidrográfica do Médio Curso do Rio Teles Pires, município de Alta Floresta, Mato Grosso.

\section{Metodologia}

\subsection{Características morfológicas e classificação dos solos}

O estudo foi conduzido na BHMTP, no município de Alta Floresta, estado de Mato Grosso (Figura 1), sendo a região intensamente percorrida no trabalho de campo, buscando-se um reconhecimento geral, tanto da paisagem, quanto do solo.

A região da BHMTP encontra-se intimamente ligada aos Planaltos Residuais do Norte de Mato Grosso que compreendem blocos de relevos separados por extensa superfície rebaixada, representados na área pelas serras do Cachimbo, a nordeste, e dos Caiabis, a sudoeste. Verifica-se, no conjunto, uma topografia aplainada e dissecada, com formas tabulares desenvolvidas sobre sedimentos suborizontalizados do Grupo Beneficente (Moreira \& Vasconcelos, 2007). Apresentam relevos residuais de topo tabular ainda conservado, delimitados por escarpas erosivas, aparecendo tanto sobre os sedimentos quanto sobre as demais litologias (Souza et al., 2004).

A primeira parte deste estudo foi, essencialmente, feita no campo, através da leitura e interpretação da paisagem em geral e atributos do solo de fácil visualização constituíram o material de estudo da dinâmica da paisagem. 
Em um segundo momento, foram abertas trincheiras em áreas de vegetação nativa utilizando-se a metodologia de Santos et al. (2018): foram abertas trincheiras de 1,2 $\mathrm{m}$ de largura, 2,0 $\mathrm{m}$ de profundidade e 1,5 m de comprimento para a observação do perfil do solo que expressa todas as características morfológica do solo na paisagem.

As amostragens dos solos para caracterização física e química foram feitas em 6 (seis) ambientes ao longo das margens direita e esquerda do Rio Teles Pires, localizados nas Fazenda Encanto da Natureza, Fazenda São José, Rio Teles Pires, Fazenda Estrada do Espanhol, Comunidade Bonfim e Fazenda Vaca Branca (Figura 1).

Para as realizações dos Blocos Diagramas e fotos panorâmicas, foram utilizados drones (veiculo não tripulado). As fotos panorâmicas foram realizadas em cada ambiente através de um plano de voo pré-estabelecido de 120 metros altitude com uma superposição de 80 × 80 metros frontal e lateral a uma velocidade de voo de $15 \mathrm{~m} / \mathrm{s}$.

Figura 1 - Localização dos Perfis para coletas de amostragem de solo na Bacia Hidrográfica do Médio Curso do Rio Teles Pires no município de Alta Floresta - MT.

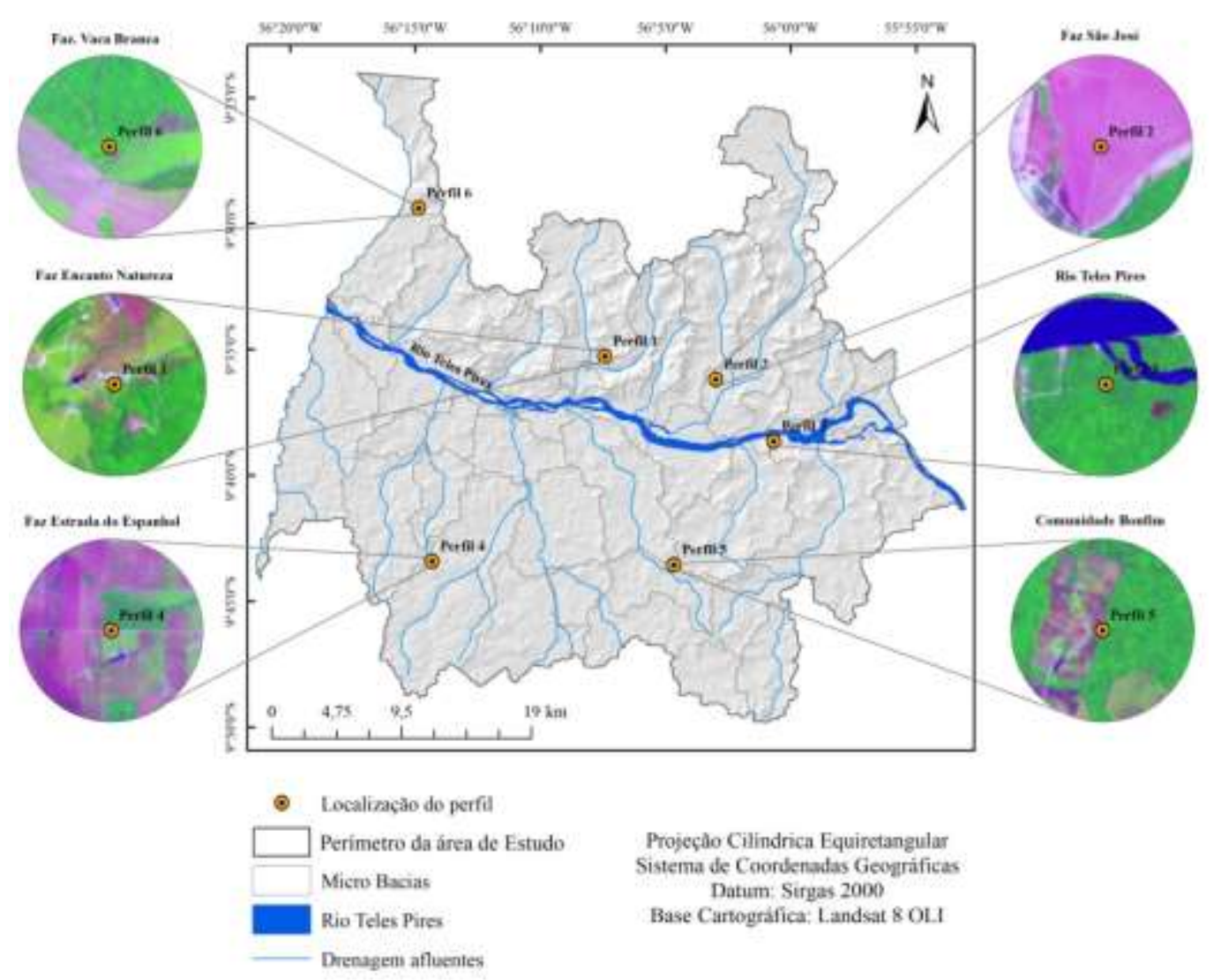

Fonte: Autores.

Em cada ambiente, foram abertas 1 (uma) trincheira (Tabela 1), no entorno dessas, trincheiras foram escolhidas, aleatoriamente, entre distâncias de 5 a $10 \mathrm{~km}$, áreas para coletas de solos nesses ambientes. Também foram coletadas amostras de cada horizonte para análises físicas e químicas. Os perfis de solo (P1, P2, P3, P4, P5 e P6) e a paisagem foram fotografados e descritos morfologicamente conforme (Santos et al., 2015). Todos os perfis de solos descritos foram classificados utilizando o Sistema Brasileiro de Classificação dos Solos (Santos et al., 2018). 
Tabela 1 - Locais das trincheiras para a descrição morfológica dos solos na Bacia Hidrográfica do Médio Curso do Rio Teles Pires, Mato Grosso.

\begin{tabular}{|c|c|c|c|}
\hline \multirow{2}{*}{$\begin{array}{c}\text { Perfil e Pontos de } \\
\text { Coletas }\end{array}$} & \multicolumn{2}{|c|}{ Coordenadas } & \multirow[t]{2}{*}{ Local } \\
\hline & Latitude & Longitude & \\
\hline Perfil 1 (P1) & $9^{\circ} 35^{\prime} 14,878^{\prime \prime} \mathrm{S}$ & $56^{\circ} 7 ’ 23,354^{\prime \prime} \mathrm{W}$ & Faz. Encanto da Natureza \\
\hline Perfil 2 (P2) & $9^{\circ} 36^{\prime} 9,411^{\prime \prime S}$ & $56^{\circ} 2^{\prime} 57,48^{\prime \prime} \mathrm{W}$ & Faz. São José \\
\hline Perfil 3 (P3) & $9^{\circ} 38^{\prime} 35,758^{\prime \prime} \mathrm{S}$ & $56^{\circ} 0 ’ 38,556^{\prime \prime} \mathrm{W}$ & Rio Teles Pires \\
\hline Perfil 4 (P4) & $9^{\circ} 43$ '23,794" S & $56^{\circ} 14^{\prime} 16,811 " \mathrm{~W}$ & Estrada do Espanhol \\
\hline Perfil 5 (P5) & $9^{\circ} 43^{\prime} 30,681 " \mathrm{~S}$ & $56^{\circ} 4 ' 36,912 " \mathrm{~W}$ & Com. Bonfim \\
\hline Perfil 6 (P6) & $9^{\circ} 29^{\prime} 22,661 " \mathrm{~S}$ & $56^{\circ} 14^{\prime} 51,374^{\prime \prime} \mathrm{W}$ & Faz. Vaca Branca \\
\hline
\end{tabular}

Fonte: Autores.

\subsection{Caracterização física do solo}

Foram coletadas amostras indeformadas em cilindros de metal para a determinação da macroporosidade e microporosidade, porosidade total e densidade do solo (Ds), segundo metodologias preconizadas em Embrapa (2017). As amostras foram encaminhadas e analisadas no Laboratório de Análise de Solos da Universidade do Estado de Mato GrossoUNEMAT, campus de Pontes e Lacerda-MT. A porosidade total se determinou a partir dos valores de densidade do solo (Ds) e densidade de partículas (Dp) pela expressão: PT = $1-(\mathrm{Ds} / \mathrm{Dp})$, microporosidade e macroporosidade foram determinados pela mesa de tensão.

Nas amostras deformadas, foram determinadas a granulometria (areia, silte e argila) e argila dispersa em água (ADA) no laboratório da Empresa Mato-grossense de Pesquisa, Assistência e Extensão Rural (EMPAER-MT). As análises granulométricas e ADA foram determinadas pelo método da pipeta e o grau de floculação da argila $\left(\mathrm{G}_{\mathrm{Flo}}\right)$ foi calculado seguindo a metodologia descrita pela Embrapa (2017).

\subsection{Caracterização química do solo}

Nas amostras de solo deformadas, Terra Fina Seca ao Ar (TFSA) foram realizadas as análises químicas de rotina, conforme segue: acidez ativa ( $\mathrm{pH}$ em $\mathrm{H}_{2} \mathrm{O}$ e em $\mathrm{KCl} 1 \mathrm{~mol} \mathrm{~L}{ }^{-1}$ ), com relação solo-solução 1:2,5; Fósforo extraído com solução Mehlich 1 na relação 1:10 e determinado por absorção atômica; Cálcio e magnésio extraídos com $\mathrm{KCl}_{1} \mathrm{~mol} \mathrm{~L}{ }^{-1}$ na proporção 1:10, determinado por absorção atômica; o potássio e o fósforo foram extraídos por solução de Mehlich-1, sendo o K determinado por fotometria de chama e o $\mathrm{P}$, por colorimetria. $\mathrm{O}$ alumínio trocável foi extraído $\mathrm{com} \mathrm{KCl}_{1} \mathrm{~mol} \mathrm{~L}^{-1}$, na proporção 1:10, e determinado por titulação com NaOH 0,025 mol L-1 (Defelipo \& Ribeiro, 1991). A acidez potencial (H + Al) foi extraída com acetato de cálcio $0,5 \mathrm{~mol} \mathrm{~L}^{-1}$, na relação $1: 15 \mathrm{com}$ pH ajustado a 7,0, e determinada por titulação com $\mathrm{NaOH}$ 0,025 mol L-1 . A matéria orgânica foi determinada através do método via úmida pela oxidação com $\mathrm{K}_{2} \mathrm{Cr}_{2} \mathrm{O}_{7} 0,0667 \mathrm{~mol} \mathrm{~L}^{-1} \mathrm{e}$ posterior titulação com sulfato ferroso amoniacal (Embrapa, 2017).

A partir dos resultados analíticos, foi determinada a soma das bases (SB), CTC efetiva, CTC a pH 7,0, a porcentagem de saturação por bases $(\mathrm{V})$ e a porcentagem de saturação por $\mathrm{Al}^{3+}$.

\section{Resultados e Discussão}

\subsection{Caracterização morfológica e classificação dos solos}

Os solos foram classificados da seguinte forma: dois ARGISSOLO VERMELHO-AMARELO Distrófico típico (PVAd), localizados sobre a margem esquerda do rio Teles Pires; dois Latossolos, LATOSSOLO VERMELHO Eutrófico típico (LVe) e LATOSSOLO VERMELHO-AMARELO Distrófico típico (LVAd), localizados à direita do rio Teles Pires; um 
GLEISSOLO HÁPLICO Tb Distrófico plintossólico (GXbd), localizado à esquerda; e um CAMBISSOLO HÁPLICO Tb Distrófico $(\mathrm{CXbd})$ à direita do rio Teles Pires. Pode-se observar a distribuição dos solos ao longo do perfil longitudinal na BHMTP da Figura 2.

Figura 2 - Perfil pedológico e ambiente de ocorrência na Bacia Hidrográfica do Médio Curso do Rio Teles Pires no município de Alta Floresta - MT.

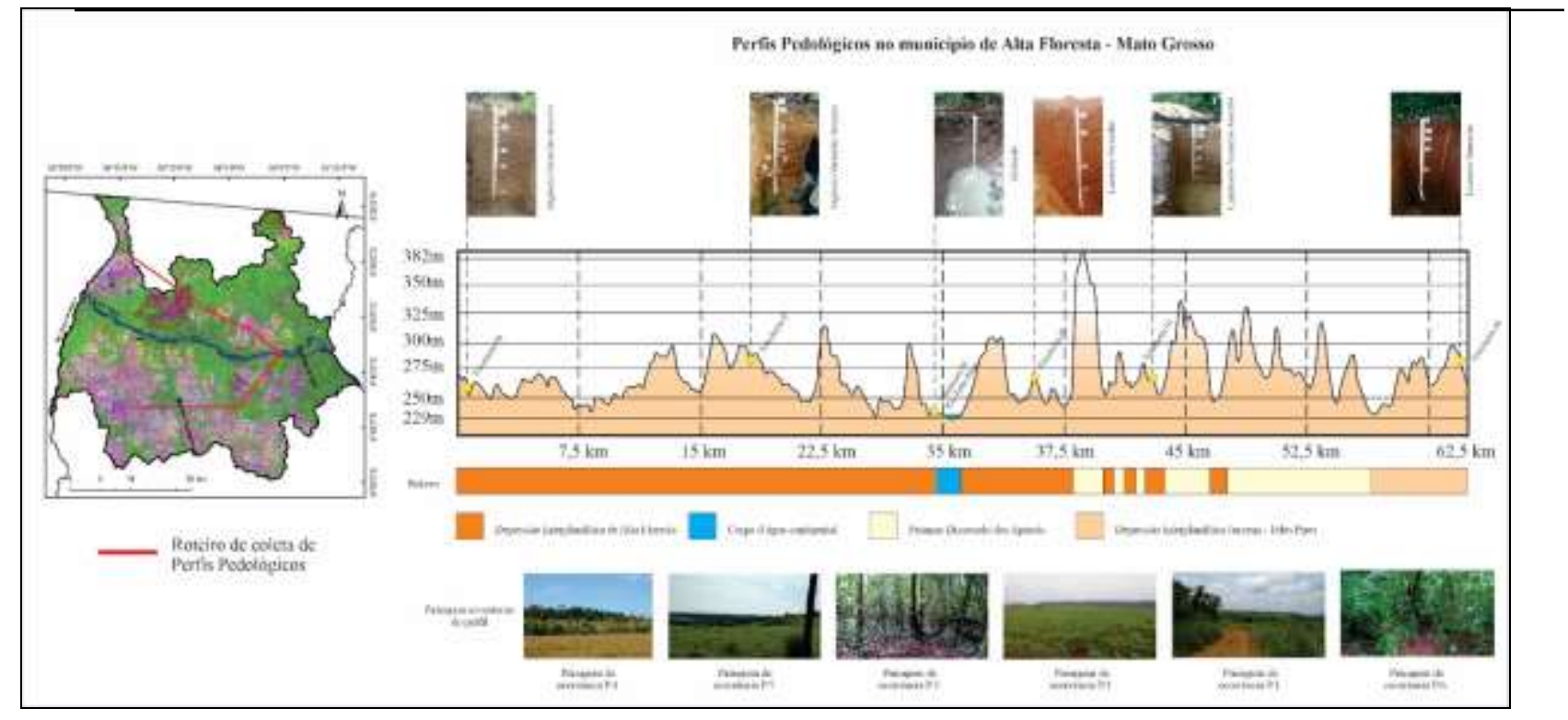

Fonte: Autores.

As cores dos perfis dos solos na BHMTP variaram entre os matizes de 2,5 YR, 5 YR, 10 YR e 10 R, conforme pode ser observado na Tabela 2 e Figura 2. Os principais agentes responsáveis pela cor do solo são a matéria orgânica e óxidos de ferro. Dessa forma a cor do solo permite inferir sobre a ocorrência de processos pedogenéticos como, plintização, latossolização e podzolização (Resende et al., 1997).

Essa coloração vermelho-amarelada é predominante em solos amazônicos devido ao alto poder pigmentante dos óxidos de ferro (principais minerais secundários presentes em solos tropicais, ao lado da caolinita), principalmente do conteúdo de sesquióxidos e óxidos de ferro não-hidratados (hematita), que dão a cor avermelhada, e óxidos de ferro hidratados (goethita), atrelada à cor amarelada do solo (Teixeira et al., 2009; Benedetti et al., 2011). A determinação da cor é importante, pois ela pode ser usada na diferenciação de horizontes, na avaliação do teor de matéria orgânica, na avaliação do grau de oxidação/hidratação dos compostos férricos e na avaliação da drenagem do perfil (Pereira et al., 2019), caracterizando, assim, um dos principais atributos morfológicos. 
Tabela 2 - Características morfológicas dos perfis dos solos estudados na Bacia Hidrográfica do Médio Curso do Rio Teles Pires no município de Alta Floresta - MT.

\begin{tabular}{|c|c|c|c|c|c|c|}
\hline Horiz. & Prof.(cm) & Cor & Textura & Estrutura & Consistência & Transição \\
\hline \multicolumn{7}{|c|}{------------Perfil 1 - CAMBISSOLO HÁPLICO Tb Distrófico - Faz. Encanto da Natureza------------- } \\
\hline Ap & $0-10$ & 10YR 7/2 & Fra & $1 \mathrm{p}$ bs & sm uf p2 pj2 & tpg \\
\hline BA & $10-22$ & 10YR 8/2 & $\mathrm{Fa}$ & $1 \mathrm{p} \mathrm{bs}$ & sm uf p2 pj2 & tpg \\
\hline $\mathrm{Bi}$ & $22-50$ & 10YR 8/3 & $\mathrm{Fa}$ & $1 \mathrm{p} \mathrm{bs}$ & sld uf p3 pj3 & tpd \\
\hline $\mathrm{C}_{1}$ & $50-70$ & $10 Y R 8 / 4$ & Fra & $1 \mathrm{p} \mathrm{bs}$ & sld uf p3 pj3 & tpd \\
\hline \multirow[t]{2}{*}{$\mathrm{C}_{2}$} & $100^{+}$ & 10YR 4/8 & $\mathrm{Ra}$ & $1 \mathrm{p} \mathrm{mç}$ & sm uf p3 pj3 & tpd \\
\hline & -----Perf & - LATOSSOI & VERMEL & Distrófico típi & Faz. São José---- & - \\
\hline Ap & $0-33$ & $2,5 \mathrm{YR} 4 / 2$ & $\mathrm{R}$ & $2 \mathrm{~m} \mathrm{bs}$ & ss uf p3 pj3 & tpd \\
\hline $\mathrm{Bw}_{1}$ & $33-100$ & 2,5YR 5/8 & $\mathrm{R}$ & $1 \mathrm{~m} \mathrm{bs}$ & ss uf $\mathrm{p} 3 \mathrm{pj} 3$ & tpd \\
\hline $\mathrm{Bw}_{2}$ & $100-152$ & 2,5 YR $5 / 8$ & $\mathrm{R}$ & $1 \mathrm{~m} \mathrm{bs}$ & ss uf $\mathrm{p} 3 \mathrm{pj} 3$ & tpd \\
\hline \multirow[t]{2}{*}{$\mathrm{Bw}_{3}$} & $152^{+}$ & 2,5YR 5/8 & $\mathrm{R}$ & $1 \mathrm{~m} \mathrm{gs} \mathrm{bs}$ & ss uf $\mathrm{p} 3 \mathrm{pj} 3$ & tpd \\
\hline & ---Perfil 3 & LEISSOLO I & PLICO Tb & strófico plintos & o - Rio Teles Pir & -- \\
\hline A & $0-15$ & Gley $18 / 10 Y$ & $\mathrm{~F}$ & $2 \mathrm{~m} \mathrm{ba}$ & sld ufi p3 pj3 & tpd \\
\hline $\mathrm{Bg}$ & $16-100^{+}$ & $10 \mathrm{GY} 7 / 2$ & $\mathrm{R}$ & $2 \mathrm{mba}$ & sld ufi p3 pj3 & tpd \\
\hline \multicolumn{7}{|c|}{---Perfil 4 - ARGISSOLO VERMELHO-AMARELO Distrófico típico - Estrada do Espanhol---- } \\
\hline Ap & $0-10$ & 10YR 4/4 & $\mathrm{Fa}$ & $1 \mathrm{p} \mathrm{bs}$ & sd umf p1 pj1 & $\operatorname{tpg}$ \\
\hline BA & 11 a 58 & 10YR 6/2 & $\mathrm{Ra}$ & $1 \mathrm{~m}$ bs & sd ufi p3 pj4 & tpd \\
\hline $\mathrm{Bt}_{1}$ & $39-75$ & $10 Y R 7 / 3$ & Fra & $1 \mathrm{p}$ bs & sd ufi p3 pj4 & tpd \\
\hline $\mathrm{Bt}_{2}$ & $76-110$ & 10YR 8/3 & Fra & $1 \mathrm{~g} / \mathrm{mg}$ bs & ss us/uf p3 pj3 & tpd \\
\hline \multirow[t]{2}{*}{$\mathrm{C}$} & $111^{+}$ & 10YR 7/2 & Fra & $1 \mathrm{mp} g s$ & ss us/uf p3 pj2 & tpd \\
\hline & -Perfil 5 - & GISSOLO VE & IELHO-A & ARELO Distróf & pico - Com. Bon & --- \\
\hline Ap & $0-10$ & $5 Y R$ 6/1 & Fra & $1 \mathrm{pgs}$ & sm umf p1 pj1 & tpc \\
\hline $\mathrm{BA}$ & $10-58$ & 5YR 6/1 & $\mathrm{R}$ & $2 \mathrm{~m} \mathrm{bs}$ & ss uf $\mathrm{p} 4 \mathrm{pj} 3$ & tpd \\
\hline $\mathrm{Bt}$ & $58-125$ & $2,5 Y R$ 7/4 & $\mathrm{R}$ & $2 \mathrm{~m} \mathrm{bs}$ & sm umf p2 pj2 & tpd \\
\hline \multirow[t]{2}{*}{$\mathrm{Cr}$} & $125^{+}$ & $5 Y R$ 6/6 & $\mathrm{Ra}$ & $3 \mathrm{~g} / \mathrm{mg} \mathrm{gs}$ & p1 pj1 & tpd \\
\hline & --Perfil 6 & TOSSOLO & MELHO & atrófico típico - & Vaca Branca---- & \\
\hline A & $0-22$ & 10R $3 / 3$ & $\mathrm{Ra}$ & $1 \mathrm{mp} \mathrm{p} \mathrm{m} \mathrm{g} \mathrm{bs}$ & sm umf p3 pj3 & tpd \\
\hline BA & $22-33$ & 10R 4/4 & $\mathrm{R}$ & $2 \mathrm{p} \mathrm{bs}$ & sm umf p3 pj2 & tpd \\
\hline $\mathrm{Bw}$ & $33-90$ & 10R 4/6 & $\mathrm{R}$ & $2 \mathrm{mp} \mathrm{p} \mathrm{m} \mathrm{g} \mathrm{bs}$ & sm umf p3 pj3 & tpd \\
\hline $\mathrm{Bw}_{2}$ & $90^{+}$ & 10R 3/6 & $\mathrm{R}$ & $2 \mathrm{p} \mathrm{m} \mathrm{bs}$ & sm umf p3 pj3 & tpd \\
\hline
\end{tabular}

Textura: a - arenoso; f - franco; fa - franco-arenoso; $r$ - argila e argilosa; fr - franco-argilosa; fs - franco-siltosa; fra - francoargiloso-arenosa; frs - franco-argilo-siltosa; ra - argilo-arenosa.

Estrutura: 1 Fraca; 2 Moderada; 3 Forte; $\mathrm{mp}$ - muito pequena; $\mathrm{p}$ - pequena; $\mathrm{m}$ - média; $\mathrm{g}$ - grande; g/mg - grande/muito grande; mç - maciça; a - angular; gs - grão-simples; gr - granular; ba - blocos angulares; bs - bloco subangulares.

Consistência: s - seca, u - úmida; ss - solta; sm - macia; sld - ligeiramente dura; sd - dura; smd -muito dura; sed extremamente dura; us - solta; umf - muito friável; uf - friável; ufi - firme; umfi - muito firme; uef - extremamente firme; p1 - não plástica; p2 - ligeiramente plástica; p3 - plástica; p4 - muito plástica; pj1 - não pegajosa; pj2 - ligeiramente pegajosa; pj3 - pegajosa; pj4 - muito pegajosa.

Transição: tpg - transição plana e gradual; tpd - transição plana e difusa; tpc - transição plana e clara. Fonte: Autores.

O perfil 1 (CXbd) corresponde à Fazenda Encanto da Natureza, o perfil 4 (PVAd) na Estrada do Espanhol e o perfil 6 (LVe) na Fazenda Vaca Branca, apresentaram Matiz 10YR. Os horizontes superficiais destes solos são de cores vermelho claro-acinzentado, vermelho-acinzentado e vermelho escuro acinzentado, para o CAMBISSOLO HÁPLICO Tb Distrófico, ARGISSOLO VERMELHO-AMARELO Distrófico típico e LATOSSOLO VERMELHO Eutrófico típico, respectivamente.

Já no perfil 2 (LVAd), na Fazenda São José, apresentou-se Matiz 2,5 YR, com Croma de 4 e 5, e Valores de 2 e 8, caracterizando em seus horizontes cores vermelho-acinzentada no horizonte superficial A e, nos horizontes subsuperficiais diagnósticos, a cor vermelha para todos os horizontes. Isso se deve em razão das condições climáticas sobre o material de origem (riolitos, riodacitos, dacitos, andesitos e rochas piroclásticas da Formação Colíder). O perfil 3 (GXbd), à margem esquerda do Rio Teles Pires, apresentou Matiz Gley 1 8/10Y, cor cinza clara esverdeada, com presença de mosqueamento no horizonte diagnóstico subsuperfical, ambiente onde ocorre intenso processo de gleização e plintitização. Esses processos de 
gleização e plintização ocorrem sob influencia de condições de saturação com água e/ou flutuação do lenções freático, indicativo de áreas mal drenadas, que acumulam água em algum momento e ou mesmo permanentemente.

No perfil 5 (PVAd), da Comunidade Bonfim, o solo apresentou Matiz 5YR e 2,5YR, com Croma variando entre 6 a 7 e Valores de 1 a 6, que se caracterizou com a cor cinzenta, bruno avermelhada escura ao amarelo avermelhado ou vermelho amarelado. Nesse caso, podem ser atribuídas as cores a heranças de seu material de origem e, também, à adição de matéria orgânica, presença de hematita e maior ocorrência de ferro oxidado hidratado.

De modo geral, a maioria dos horizontes dos perfis apresentaram estrutura do tipo blocos angulares e grãos simples, com graus de desenvolvimento fraco a moderado (Tabela 2). Resultados semelhantes são citados por (Campos et al., 2012; Góis Orrutéa et al., 2012).

Em relação à consistência, os perfis dos solos na BHMTP foram predominante macios, com ocorrência de consistências solta, dura, friável ao longo dos horizontes. A pegajosidade e a plasticidade variaram entre ligeiramente plástica e plástica, ligeiramente pegajosa e pegajosa, entre os horizontes dos perfis dos solos.

Benedetti et al. (2011) estudaram solos em Roraima, no norte amazônico, e relatam consistência úmida em solos de textura arenosa, que apresentaram consistência do tipo solta e, quando molhada, não plástica e não pegajosa, para os solos de textura média, foi do tipo muito friável a friável (úmido) e ligeiramente plástico e ligeiramente pegajoso.

Quanto à transição dos horizontes dos perfis das classes de solos estudadas, de modo geral, em todos horizontes, apresenta-se transição plana e difusa.

\subsection{Características físicas dos solos}

O Perfil 1 (CXbd), em análise morfológica de campo e corrigidas com as análises de laboratório, apresentou textura franco-argilo-arenosa no horizonte $\mathrm{A}$ e $\mathrm{C}$, franco-arenosa nos horizontes $\mathrm{BA}$ e $\mathrm{Bi}$, e argilo-arenosa no horizonte $\mathrm{C}_{1}$ (Tabela 2 e 3). Observou-se, no perfil 1, maior quantidade de areia quando comparado com silte e argila, representando neste perfil textura arenosa e, portanto, menor disponibilidade de reter água ao longo do perfil e maior aeração. Reis et al. (2007), pesquisando a variação da composição granulométrica e orgânica em uma topossequência no Pará, encontraram em Cambissolo fração de areia elevadas, semelhante a esse estudo.

No Perfil 2 (LVAd), em todos os horizontes, apresentou-se textura argila e argilosa. Já o GXbd (Perfil 3) no horizonte $\mathrm{A}$, apresentou textura franco, e, no horizonte $\mathrm{Bg}$, característica textural argila e argilosa.

Os Perfis 4 e 5 (PVAd) apresentaram texturas franco-arenoso para franco-argiloso-arenosa no horizonte A, argiloarenosa no horizonte $\mathrm{BA}$, franco-argiloso-arenosa para os horizontes $\mathrm{Bt}_{1}, \mathrm{Bt}_{2}$ e $\mathrm{C}$ do perfil 4 e franco-argiloso-arenosa para $\mathrm{o}$ horizonte A, argila para o horizontes BA e Bt e argilo-arenosa para o horizonte $\mathrm{Cr}$ do perfil 5. Os Argissolos com textura arenosa não são um fato atípico para a região Amazônica. Santos et al., (2018) explicam que solos Argissolos apresentam a elevada presença de frações areias nos horizontes A. O Perfil 6 (LVe) apresentou textura argilo-arenosa, no horizonte A, e argila e argilosa nos horizontes subsequentes $\mathrm{BA}, \mathrm{Bw}_{1}$ e $\mathrm{Bw}_{2}$.

Os perfis dos solos estudados, conforme o triângulo textural adotado pela Sociedade Brasileira de Ciência do Solo (Santos et al., 2015), no geral, são solos de textura média (Tabela 3), o que, aliado à estrutura do solo, permitem, quando comparados a um solo arenoso, manter maior disponibilidade de água para plantas, propiciam o desenvolvimento do sistema radicular em profundidade e drenam fácil o excesso de água (Salton et al., 2014), características estas desejáveis para o manejo de solos.

Quanto à relação silte/argila dos solos estudados (Tabela 3), estes apresentaram alto grau de intemperismo, visto que a maioria dos horizontes apresentaram valores inferiores a 0,7 nos solos de textura média e valores inferiores a 0,6 nos solos de textura argilosa ou muito argilosa. 
Tabela 3 - Características físicas dos perfis do solo na Bacia Hidrográfica do Médio Curso do Rio Teles Pires no município de Alta Floresta - MT.

\begin{tabular}{|c|c|c|c|c|c|c|c|c|c|c|c|}
\hline \multirow{3}{*}{ Horiz. } & \multirow{3}{*}{$\begin{array}{l}\text { Prof. } \\
\text { Cm }\end{array}$} & \multirow{3}{*}{ Areia } & \multirow{3}{*}{ Silte } & \multirow{3}{*}{$\begin{array}{c}\text { Argil } \\
\mathbf{a} \\
---\end{array}$} & \multirow{3}{*}{$\begin{array}{c}\text { Relação } \\
\text { Silte/Argila } \\
\text { g kg }^{-1} \\
\end{array}$} & \multirow{3}{*}{$\begin{array}{c}\text { Ds } \\
\mathrm{Mg} \mathrm{m}^{-3}\end{array}$} & \multicolumn{3}{|c|}{ Porosidade } & \multirow{3}{*}{$\begin{array}{l}\text { ADA } \\
\text { g kg-1 }^{-1} \\
\end{array}$} & \multirow{3}{*}{$\begin{array}{r}\text { GFlo } \\
\%\end{array}$} \\
\hline & & & & & & & & Macro & Micro & & \\
\hline & & & & & & & \multicolumn{3}{|c|}{ 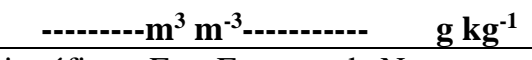 } & & \\
\hline & & \multicolumn{10}{|c|}{------Perfil 1 - CAMBISSOLO HÁPLICO Tb Distrófico - Faz. Encanto da Natureza------ } \\
\hline Ap & $0-10$ & 680 & 120 & 200 & 0,6 & 1,29 & 0,391 & 0,104 & 0,287 & 60 & 70 \\
\hline BA & $10-22$ & 680 & 140 & 180 & 0,7 & 1,26 & 0,370 & 0,116 & 0,255 & 80 & 55 \\
\hline $\mathrm{Bi}$ & $22-50$ & 620 & 200 & 180 & 1,1 & 1,32 & 0,373 & 0,126 & 0,247 & 120 & 33 \\
\hline $\mathrm{C}_{1}$ & $50-70$ & 620 & 120 & 260 & 0,4 & 1,32 & 0,355 & 0,142 & 0,214 & 160 & 38 \\
\hline \multirow[t]{2}{*}{$\mathrm{C}_{2}$} & $100^{+}$ & 480 & 60 & 460 & 0,1 & 1,48 & 0,359 & 0,106 & 0,253 & 20 & 95 \\
\hline & \multicolumn{10}{|c|}{--------Perfil 2 - LATOSSOLO VERMELHO Distrófico típico - Faz. São José------------ } & \\
\hline Ap & $0-33$ & 320 & 120 & 560 & 0,2 & 1,25 & 0,451 & 0,151 & 0,300 & 80 & 86 \\
\hline $\mathrm{Bw}_{1}$ & $33-100$ & 320 & 100 & 580 & 0,1 & 1,12 & 0,472 & 0,156 & 0,317 & 80 & 86 \\
\hline $\mathrm{Bw}_{2}$ & $100-152$ & 320 & 100 & 580 & 0,1 & 1,16 & 0,456 & 0,14 & 0,318 & 20 & 96 \\
\hline \multirow[t]{2}{*}{$\mathrm{Bw}_{3}$} & $152^{+}$ & 400 & 80 & 520 & 0,1 & 1,10 & 0,450 & 0,171 & 0,279 & 20 & 96 \\
\hline & \multicolumn{11}{|c|}{-----Perfil 3 - GLEISSOLO HÁPLICO Tb Distrófico plintossólico - Rio Teles Pires------------ } \\
\hline A & $0-15$ & 320 & 420 & 260 & 1,6 & 1,01 & 0,451 & 0,146 & 0,305 & 120 & 54 \\
\hline \multirow[t]{2}{*}{$\mathrm{Bg}$} & $15-100^{+}$ & 340 & 240 & 420 & 0,5 & 1,51 & 0,356 & 0,072 & 0,284 & 200 & 52 \\
\hline & \multicolumn{11}{|c|}{-------Perfil 4 - ARGISSOLO VERMELHO-AMARELO Distrófico típico - Estrada do Espanhol---- } \\
\hline Ap & $0-10$ & 720 & 120 & 160 & 0,7 & 1,25 & 0,355 & 0,163 & 0,192 & 40 & 75 \\
\hline BA & $10-58$ & 540 & 80 & 380 & 0,2 & 1,23 & 0,348 & 0,112 & 0,236 & 60 & 84 \\
\hline $\mathrm{Bt}_{1}$ & $58-75$ & 620 & 120 & 260 & 0,4 & 1,16 & 0,409 & 0,139 & 0,270 & 60 & 77 \\
\hline $\mathrm{Bt}_{2}$ & $75-110$ & 640 & 160 & 200 & 0,8 & 1,19 & 0,443 & 0,157 & 0,286 & 20 & 90 \\
\hline \multirow[t]{2}{*}{$\mathrm{C}$} & $110^{+}$ & 640 & 140 & 220 & 0,6 & 1,05 & 0,471 & 0,192 & 0,279 & 160 & 27 \\
\hline & \multicolumn{11}{|c|}{---------Perfil 5 - ARGISSOLO VERMELHO-AMARELO Distrófico típico - Com. Bonfim-------- } \\
\hline Ap & $0-10$ & 660 & 60 & 280 & 0,2 & 1,29 & 0,358 & 0,138 & 0,220 & 100 & 64 \\
\hline BA & $10-58$ & 440 & 40 & 520 & 0,0 & 1,27 & 0,372 & 0,163 & 0,209 & 0 & 0 \\
\hline $\mathrm{Bt}$ & $58-125$ & 400 & 60 & 540 & 0,1 & 1,37 & 0,358 & 0,124 & 0,234 & 100 & 81 \\
\hline \multirow[t]{2}{*}{$\mathrm{Cr}$} & $125^{+}$ & 540 & 100 & 360 & 0,2 & 0,00 & 0,000 & 0,000 & 0,000 & 0 & 0 \\
\hline & \multicolumn{11}{|c|}{-----------Perfil 6 - LATOSSOLO VERMELHO Eutrófico típico - Faz. Vaca Branca----------- } \\
\hline A & $0-22$ & 520 & 100 & 380 & 0,2 & 1,02 & 0,508 & 0,176 & 0,332 & 40 & 89 \\
\hline $\mathrm{BA}$ & $22-33$ & 420 & 140 & 440 & 0,3 & 0,97 & 0,447 & 0,170 & 0,277 & 40 & 91 \\
\hline $\mathrm{Bw}_{1}$ & $33-90$ & 340 & 160 & 500 & 0,3 & 1,13 & 0,470 & 0,142 & 0,328 & 20 & 96 \\
\hline $\mathrm{Bw}_{2}$ & $90^{+}$ & 300 & 120 & 580 & 0,2 & 1,17 & 0,502 & 0,152 & 0,350 & 20 & 96 \\
\hline
\end{tabular}

Fonte: Autores.

A relação silte/argila apresentada na Tabela 3 mostrou baixos valores em profundidade principalmente nos Argissolos e Latossolos, o que é considerado comum, uma vez que são solos bem desenvolvidos, que, associados aos processos de intemperismo químico durante as altas precipitações da região, torna-os característicos como solos profundos e maduros. A relação silte/argila mostra a evolução no grau de intemperismo que ocorre durante o perfil de um solo. O maior valor registrado foi encontrado na camada superficial do perfil 3 (GXbd), com 1,6 $\mathrm{g} \mathrm{kg}^{-1}$, sendo na camada subsuperficial deste mesmo solo uma redução para $0,5 \mathrm{~g} \mathrm{~kg}^{-1}$. De acordo com Santos et al. (2018), a relação silte/argila é utilizada como base para avaliar o estádio do grau de intemperismo de solos tropicais e diferenciação entre horizontes B latossólicos e B incipientes.

Tais resultados são semelhantes aos verificados em outros solos da região amazônica. Andrade et al. (1997) estudaram relação de silte/argila de uma sequência Latossolo no estado do Amazonas e concluíram que a relação silte/argila apresentou valores baixos $(<0,7)$ nos horizontes ao longo da encosta (todos os perfis), sendo os valores dessa relação mais elevados (> 1,0) nas partes mais profundas dos perfis.

Barros (2013), estudando as características de solos ao longo de uma litossequência no oeste do Pará, Amazônia Oriental, encontrou valores de relação silte/argila baixos em horizontes superficiais e subsuperficiais $(<0,7)$. O autor atribui que tais valores podem estar relacionados com a natureza do material de origem. 
Os valores da Ds neste trabalho variaram de 0,97 a $1,51 \mathrm{Mg} \mathrm{m}^{-3}$ (Tabela 3). No trabalho de Monteiro et al. (2006), estudando 4 perfis de Argissolos amarelos em solos amazônicos, a densidade do solo variou de 1,19 a 1,67 Mg m ${ }^{-3}$ Segundo Vieira et al. (2000), a densidade dos solos amazônicos geralmente encontra-se na faixa entre 1,2 a 1,8 $\mathrm{Mg} \mathrm{m}^{-3}$. No perfil 3 (GXbd) e perfil 6 (LVe), apresentam-se nos horizontes superficiais, os menores valores de Ds, já os maiores se encontraram no perfil 1 (CXbd) e perfil 5 (PVAd).

Nos horizontes superficiais, os menores valores obtidos correspondem aos perfil 3 (GXbd) e perfil 6 (LVe), as quais são áreas naturais preservadas sem nenhuma presença antrópica, seguindo-se a áreas com uso de cultivos de soja perfil 2 (LVAd) e perfil 4 (PVAd), situadas em um fragmento de mata de beira de estrada com uso de pastagem, os maiores valores foram encontrados no perfil 1 (CXbd) e perfil 5 (PVAd), ambas as áreas correspondem a áreas naturais próximos de uso de pastagens.

À medida que o solo sofre intervenções no uso, ocorrem modificações nos seus atributos físicos, como o aumento da densidade do solo, diminuição da porosidade total, distribuição do diâmetro dos poros, alteração na agregação e no teor de matéria orgânica (Oliveira et al., 2013). Estudos dos indicadores da qualidade de Latossolos relacionados à degradação de pastagens relevaram que a Ds diminuiu com a profundidade, o que pode estar relacionado ao tráfego de animais, que pode provocar aumento da Ds em superfície, sobretudo na camada de 0,00-0,05 m de profundidade (Lisbôa et al., 2016).

Outro fator importante que deve ser mencionado, quanto aos estudos da Ds, é a relação direta da compactação do solo. A compactação do solo é um processo evolutivo caracterizado pelo aumento da Ds e diminuição da porosidade total, pelo rearranjo estrutural das partículas do solo (Reichert et al., 2009). Valores de Ds encontrados nesse estudo evidenciam que, até o presente momento, essa propriedade do solo, tão importante quando se pensa no desenvolvimento do sistema radicular das plantas e outras funções do solo, não está degradada.

Os resultados médios de porosidade total (PT), macroporosidade (Macro) e microporosidade (Micro) do solo são encontrados na Tabela 3. De acordo com Kiehl (1979), os solos “ideais” são aqueles que contém 1/3 de macroporos (34\%) e 2/3 de microporos (66\%). Observa-se que, em geral, nos perfis estudados, as porosidades totais são semelhantes, variando entre $0,348 \mathrm{~m}^{3} \mathrm{~m}^{-3}$ a $0,507 \mathrm{~m}^{3} \mathrm{~m}^{-3}$. Os valores médios de macroporidade e microporidade foram, respectivamente, de $33,67 \%$ e $66,33 \%$, para todos os perfis estudados, esses valores podem estar atribuídos a texturas dos solos, que, em sua maioria, apresentaram texturas franco-argiloso-arenoso, franco-arenoso e argilo-arenosa.

Barros et al. (2012) estudaram as características de solos amazônicos e encontraram valores de macroporos superiores a $10 \mathrm{~m}^{-3} \mathrm{~m}^{-3}$, esses valores são considerados limite inferior para a adequada difusão de oxigênio, demonstrando que se garante, então, uma boa aeração para o desenvolvimento de raízes, também relatam que, de acordo com a distribuição do tamanho de poros, houve predomínio do volume de microporos nas áreas estudadas, representando cerca de 70, 63 e $69 \%$ dos poros totais. Esses resultados corroboram com esse estudo, pois, em todos os perfis estudados na BHMTP, obtiveram-se resultados semelhantes de poros totais (Tabela 3).

Os dados de argila dispersa em água (ADA) e o grau de floculação $\left(\mathrm{G}_{\mathrm{Flo}}\right)$ mostram uma grande variação entre os perfis, em todos os horizontes, conforme a Tabela 3. Segundo Santos et al. (2010), o conhecimento da argila dispersa em água (ADA) e do grau de floculação (GF) são essenciais para estudos conservacionistas, já que o primeiro contribui para a formação de camadas adensadas/compactadas e o segundo está relacionado à agregação das partículas do solo. Altos valores de ADA e

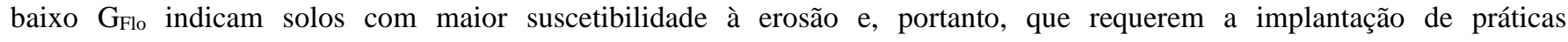
conservacionistas no sentido de se evitar sua degradação, bem como o comprometimento dos recursos hídricos.

A ADA, no perfil 1 (CXbd), apresenta um aumento nas profundidades dos horizontes A, BA, Bi e $\mathrm{C}_{1}$; já no horizonte $\mathrm{C}_{2}$, houve uma diminuição de ADA, observa-se que quanto maior é a dispersão de argila, menor é o grau de floculação. Já no perfil 2 (LVAd), apresentou-se um comportamento com valores elevados de ADA, bem como valores altos de $\mathrm{G}_{\mathrm{Flo}}$, nos 
horizontes $\mathrm{A}$ e $\mathrm{Bw}_{1}$; já os horizontes $\mathrm{Bw}_{2}$ e $\mathrm{Bw}_{3}$ apresentaram valores baixos de $\mathrm{ADA}$, consequentemente, maiores valores de $\mathrm{G}_{\text {Flo }}$.

Para o perfil 3 (GXbd), houve um aumento de ADA no horizonte subsuperficial Bg e diminuição de G foram bastante semelhantes os resultados dos horizontes A e Bg. No perfil 4 (PVAd), apresentaram-se valores diferentes de

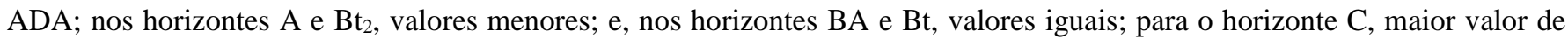
ADA. Já o perfil 5 (PVAd) apresentou valores semelhantes entre os horizontes A e Bt e não apresentaram valores de ADA os horizontes BA e Cr. No perfil 6 ( $\mathrm{LVe}$ ), os valores de ADA são iguais para os horizontes A e BA, valores mais altos do que os horizontes $\mathrm{Bw}_{1}$ e $\mathrm{Bw}_{2}$ (Tabela 2).

Contudo, chama a atenção o fato de que, quanto maiores forem as porcentagens de $\mathrm{G}_{\text {Flo }}$, mais estáveis serão os agregados, portanto, os solos estudados apresentam valores altos de $\mathrm{G}_{\text {Flo }}$ em seus horizontes, são solos bastante estruturados, fato que os torna mais resistentes à erosão. Campos et al. (2011), em sua área de estudo, encontram teores de grau de floculação acima de $90 \%$, indicando estabilidade dos solos quanto a erosão.

\subsection{Características químicas dos solos}

Os resultados revelaram que, na Tabela 4, os valores de $\mathrm{pH}$ em água em todos os perfis, exceto o perfil 4 (PVAd) e o perfil 6 (LVe), na camada superficial, apresentaram acidez muito elevada (<4,5), de acordo com Ribeiro et al. (1999) para classificação química, já, na classificação agronômica, representaram acidez muita baixa. Quando comparados com o proposto por Souza \& Lobato (2004) para pH extraído com solução salina, todos os perfis apresentaram acidez muito alta $(<4,3)$ exceto o perfil 6 (LVe).

Para Reis et al. (2009), a principal causa dos baixos valores de pH nos solos da região amazônica é a elevada perda de bases trocáveis e consequente concentração de íons $\mathrm{H}^{+}$no solo, provocada pelo processo de intemperismo influenciado pelas altas temperaturas e longos períodos de precipitação. Silva Júnior, Boechat \& Carvalho (2012) explicam que os solos da região amazônica são naturalmente ácidos e o processo de degradação da matéria orgânica e sua rápida mineralização, causam acidificação natural do solo nesses ambientes.

Os valores de $\Delta \mathrm{pH}$ são negativos em todos os perfis, indicando o predomínio de cargas negativas na superfície dos coloides do solo, exceto para os horizontes $\mathrm{Bw}$ e $\mathrm{Bw}_{2}$ do perfil 2 (LVAd), os quais apresentaram $\Delta \mathrm{pH}$ positivos, no horizonte A do perfil 3 (GXbd), o qual apresentou delta pH zero, e o horizonte A do perfil 5 (PVAd) também apresentou delta pH positivo, ou seja, esses horizontes indicam um solo de predominância de cargas positivas, capazes de adsorver mais ânions do que cátions, considerados solos de baixa fertilidade natural (Tabela 4). 
Tabela 4 - Características químicas dos perfis dos solos na Bacia Hidrográfica do Médio Curso do Rio Teles Pires no município de Alta Floresta - MT.

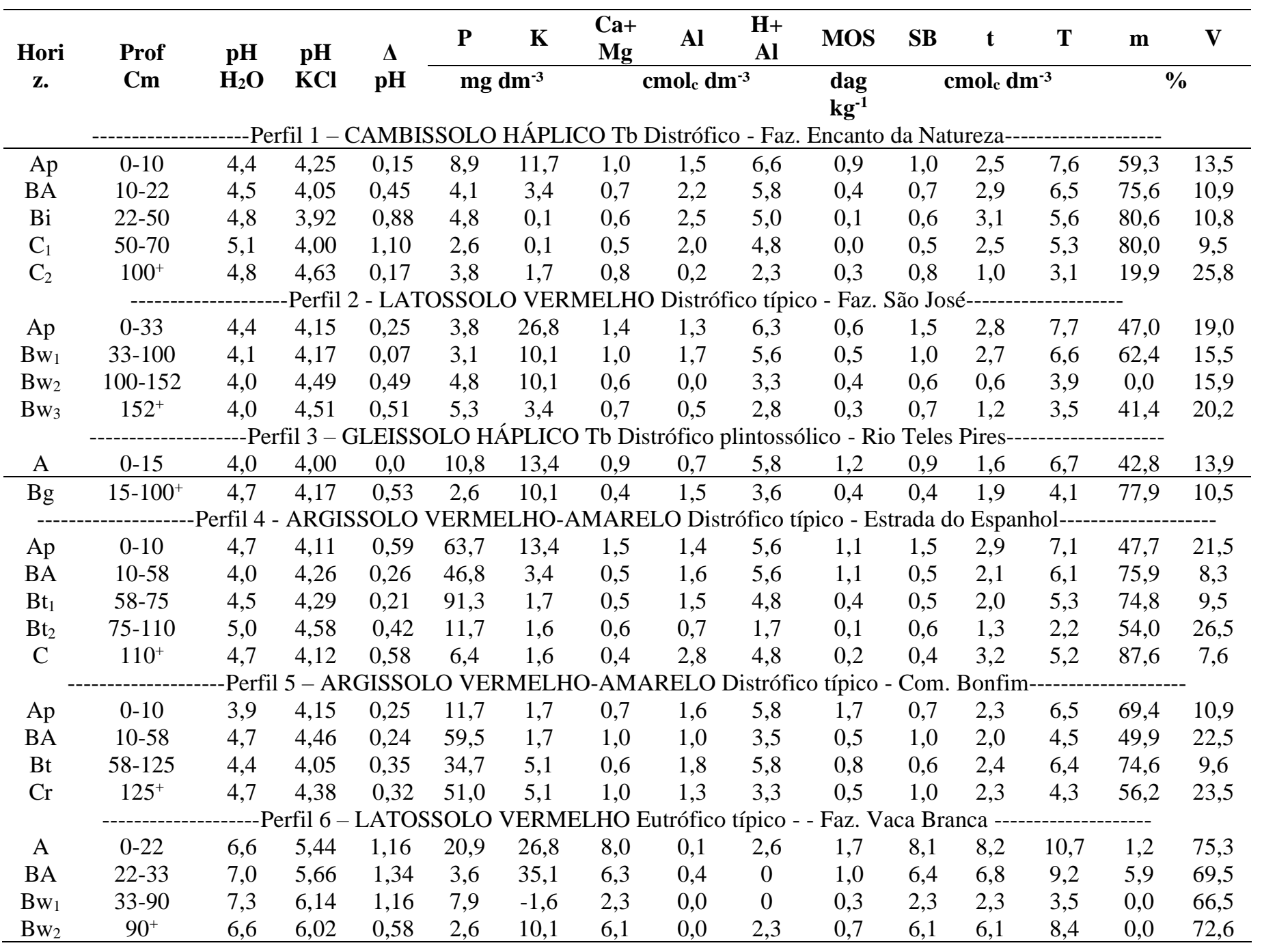

Fonte: Autores.

Observou-se, na Tabela 4 uma variação de teores no perfil de cada solo avaliado, cujas maiores concentrações são registradas no perfil 4 (PVAd) e perfil 5 (PVAd) em profundidade e na camada superficial do perfil 6 (PVAd).

Os teores de fósforo disponíveis, de acordo com o teor de argila, podem ser considerados baixos a muito baixos (Ribeiro et al., 1999) no perfil 1 (CXbd), perfil 2 (LVAd) e perfil 3 (GXbd). Pereira et al. (2018), estudando fertilidade de solos em Rondônia, constatam que o fósforo apresentou baixo em todos os tipos de uso e profundidades avaliadas, pois encontraram valores mínimo de $1 \mathrm{mg} \mathrm{dm}^{-3}$ a um valor máximo de $2 \mathrm{mg} \mathrm{dm}^{-3}$ nesses solos amazônicos. E o fósforo apresentou valores mais elevados, considerada muito boa a sua disponibilidade nos perfis 4 (PVAd), 5 (PVAd) e 6 (LVe) (Tabela 4).

O padrão de comportamento do P com o solo é dependente do tipo de solo, textura do solo, mineralogia da fração argila e da cristalografia dos minerais, condições que podem ser variáveis de região para região em função das condições locais influenciarem no tipo e composição dos diferentes solos (Barbosa, 2017). Novais \& Smyth (1999) firmam que a maioria dos solos das regiões tropicais contém baixo teor de fósforo total e muito pouco fósforo disponível para as plantas. Vilar \& Vilar (2013) concluíram que o comportamento do P no solo e na planta depende de propriedades mineralógicas do solo.

Os teores de $\mathrm{K}^{+}$nos perfis foram considerados muito baixo a baixo (Ribeiro, et al. 1999; Villar, 2007). Nos horizontes superficiais, variaram de $1,7 \mathrm{mg} \mathrm{dm}^{-3}$ de solo no horizonte A do perfil 5 (PVAd) a 26,8 $\mathrm{mg} \mathrm{dm}^{-3}$ nos horizontes A dos perfis 2 
(LVAd) e 6 (LVe). Nos horizontes subsuperficiais, os teores variam de 1,6 $\mathrm{mg} \mathrm{dm}^{-3}$ no horizonte $\mathrm{Bw}$ do perfil 6 (LVe), 1,0 $\mathrm{mg}$ $\mathrm{dm}^{-3}$ de solo para horizonte Bi do perfil 1 (CXbd), para os horizontes Bw do perfil 2 (LVAd), horizonte Bg do perfil 3 (GXbd) apresentaram valores iguais de $10,1 \mathrm{mg} \mathrm{dm}^{-3} \mathrm{de} \mathrm{K}^{+}$nos solos (Tabela 4).

Os teores $\mathrm{K}$ apresentaram, na maioria dos perfis estudados, valores baixos, visto que valores adequados são 50,01 mg $\mathrm{dm}^{-3}$ a $80 \mathrm{mg} \mathrm{dm}^{-3}$ (Ribeiro et al., 1999). Os horizontes que apresentaram maiores valores de $\mathrm{K}$ foram A e BA do perfil 6 (LVe), 26,8 $\mathrm{mg} \mathrm{dm}^{-3}$ a 35,1 mg dm${ }^{-3}$. Segundo Villar (2007), os teores altos de potássio indicam presença de minerais primários e pouco intemperismo, o que ocorre em solos de regiões mais secas e teores mais baixos de potássio indicam solos mais intemperizados, colaborando com resultados apresentados na Tabela 4.

Volf (2015) estudou as formas e disponibilidade de potássio nos solos do Vale do Araguaia e concluiu que os solos do município de Nova Xavantina apresentam teores elevados de K não-trocável. Neste estudo foram encontradas baixas concentrações de $\mathrm{K}$, o que é considerado normal em solos altamente intemperizados.

Para os valores de $\mathrm{Ca}+\mathrm{Mg}$, houve pequenas variações nos horizontes superficiais nos perfis 1 (CXbd), 2 (LVAd), 3 (GXbd), 4 (PVAd) e 5 (PVAd), em média, de $0,7 \mathrm{~g}_{\mathrm{dm}} \mathrm{dm}^{-3}$ a $1,5 \mathrm{~g} \mathrm{dm}^{-3}$, considerados como valores baixos. Já o horizonte A, do perfil 6 (LVe), apresentou um valor alto de $8,0 \mathrm{~g} \mathrm{dm}^{-3} \mathrm{de} \mathrm{Ca}+\mathrm{Mg}$ do solo, segundo Villar (2007) e Ribeiro et al. (1999).

Os solos estudados na BHMTP apresentaram $\mathrm{Ca}+\mathrm{Mg}$ baixos nos horizontes dos perfis dos solos CXbd, LVAd, GXbd e nos dois PVAd, podendo estar relacionados com o excesso de acidez do solo, refletindo elevados teores de $\mathrm{Al}^{+}$(Tabela 4). Silva Júnior et al. (2012) encontraram resultados semelhantes estudando atributos químicos do solo sob conversão de floresta amazônica para diferentes sistemas na região norte do Pará, nos quais os teores de $\mathrm{Ca}+\mathrm{Mg}$ apresentaram, na maioria dos tratamentos, valores de baixos a bom e médio.

A acidez potencial $(\mathrm{H}+\mathrm{Al})$, nos solos estudados, apresentou valores baixos, médios e altos. Os valores para o perfil 1 (CXbd), nos horizontes A e BA (6,6 a 5,8 $\left.\mathrm{cmol}_{\mathrm{c}} \mathrm{dm}^{-3}\right)$, são considerados valores altos; nos horizontes Bi e C (5,0 a 4,8 $\mathrm{cmol}_{\mathrm{c}}$ $\mathrm{dm}^{-3}$ ), estão entre os valores médios; e, no $C_{1}$, apresentou valor $2,3 \mathrm{cmol}_{\mathrm{c}} \mathrm{dm}^{-3}$, considerado um valor baixo. No perfil 2 (LVAd), os valores foram considerados altos e médios, variando entre 6,3 a 2,8 $\mathrm{cmol}_{\mathrm{c}} \mathrm{dm}^{-3}$. Para o perfil 3 (GXbd), obtiveramse valores altos e médios de acidez potencial (Tabela 3). Os valores do perfil 4 (PVAd) foram considerados altos e médios em seus horizontes, somente no horizonte $\mathrm{Bt}_{2}$, apresentou-se valor baixo de $1,7 \mathrm{cmol}_{\mathrm{c}} \mathrm{dm}^{-3}$. Já o perfil 5 (PVAd), considerando os valores de alto e médio $\left(5,8\right.$ a 3,3 $\left.\mathrm{cmol}_{\mathrm{c}} \mathrm{dm}^{-3}\right)$, as médias entres os horizontes e o perfil 6 (LVe) nos horizontes A e BA foram considerados valores médios e, nos horizontes $\mathrm{Bw}_{1}$ e Bw2, valores baixos (Ribeiro et al., 1999). De acordo com Souza \& Souza (2006), a maioria dos solos tropicais possui naturalmente baixa fertilidade e elevada acidez.

Para a matéria orgânica do solo (MOS), todos os perfis e horizontes estudados apresentaram valores entre 0,3 a 1,7 dag $\mathrm{kg}^{-1}$ (Tabela 4), classificados como baixo a muito baixo de acordo com Ribeiro et al. (1999). O mesmo autor explica que valores de MOS compreendendo entre 0,01 - 4,0 (médio), 4,01 - 7,0 (bom) e > 7,00 dag kg-1 (muito bom), são considerados solos com matéria orgânica adequada.

A matéria orgânica, por relacionar-se a inúmeras propriedades do solo e ser facilmente alterada pelo manejo agrícola, é um dos principais indicadores da qualidade do solo (Costa et al., 2013).

Os valores de Soma de bases (SB), Capacidade de Troca Iônica Efetiva (t) e Capacidade de Troca Catiônica a pH 7,0 (T), Saturação de alumínio (m) e Saturação de bases (V) refletem as diferenças já discutidas para $\mathrm{Ca}^{+2}, \mathrm{Mg}^{+2}, \mathrm{~K}^{+}, \mathrm{Al}^{+3}, \mathrm{H}^{+}$. A soma de base para todos os perfis 1 (CXbd), 2 (LVAd), 3 (GXbd), 4 (PVAd) e 5 (PVAd), em todos os horizontes, foram consideradas baixas, com valores de $0,5 \mathrm{cmol}_{\mathrm{c}} \mathrm{dm}^{-3}$ a $1,5 \mathrm{cmol}_{\mathrm{c}} \mathrm{dm}^{-3}$, cujos maiores valores foram encontrados perfil 6 (LVe) nos horizontes A, BA e Bw2, valores considerados muitos bons, $8,1 \mathrm{cmol}_{\mathrm{c}} \mathrm{dm}^{-3} \mathrm{a} 6,4 \mathrm{cmol}_{\mathrm{c}} \mathrm{dm}^{-3}$. Os valores de CTC efetiva (t) variam de 1,01 $\mathrm{cmol}_{\mathrm{c}} \mathrm{dm}^{-3}$ a $8,21 \mathrm{cmol}_{\mathrm{c}} \mathrm{dm}^{-3}$, são valores considerados baixos e muito bom (Ribeiro et al.,1999), porém, a 
maioria dos perfis apresentaram valores baixos, exceto para o perfil 6 (LVe), o qual apresentou, nos horizontes $\mathrm{A}$, $\mathrm{BA}$ e $\mathrm{Bw}_{2}$, teores mais elevados, conforme Tabela 4.

Os valores de CTC total (T) variaram de 2,2 a 10,7 $\mathrm{cmol}_{\mathrm{c}} \mathrm{dm}^{-3}$, valores esses considerados baixos e bom, respectivamente. A saturação por bases variou de 7,3 a 26,5 \%, ambos considerados muito baixo e baixo para os perfis 1 (CXbd), 2 (LVAd), 3 (GXbd), 4 (PVAd) e 5 (PVAd), cuja saturação por base pode ser atribuída como caráter distrófico. Já o perfil 6 (LVe) apresentou, em seus horizontes, valores de V entre 75,3\% a 66,5 \%, considerados eutróficos. A saturação por alumínio (m) foi considerada muito alta (Ribeiro et al., 1999) em todos os solos avaliados, exceto no LVe.

Marques et al. (2004), estudando os parâmetros físicos, químicos e hídricos de um Latossolo Amarelo, na região Amazônica, encontraram baixa saturação por base (V\%) e alta saturação por alumínio (m).

\subsection{Distribuição do solo na paisagem, potencial e limitação para o uso}

A distribuição dos solos na paisagem é representada pelos blocos diagramas ao longo da BHMTP no município de Alta Floresta/MT (Figura 3), na qual se pode observar o CAMBISSOLO HÁPLICO Tb Distrófico (CXbd), no ambiente denominado Fazenda Encanto da Natureza, cuja paisagem é marcada por relevo suave ondulado com afloramentos de rochas.

Os Cambissolos são solos pouco desenvolvidos com horizonte B incipiente, pedogênese pouco avançada, ausência ou quase ausência da estrutura da rocha, apresentam grande variação no tocante à profundidade, ocorrendo desde rasos a profundos, além de apresentarem grande variabilidade também em relação às demais características (Santos et al., 2018).

Esses solos, na BHMTP, são oriundos geologicamente de rochas granitoides distintas em rochas vulcânicas do Grupo Colíder (Silva Santos, 2018). O CXbd estudado é encontrado em relevo suave ondulado (Figura 3), condição que favorece a mecanização no local quando não há presença de cascalhos ou pedregosidade. O uso, na localidade, atualmente, é com pastagens e plantio de Neem (Azadirachta indica) para fabricação de sabonetes, conforme o bloco diagrama mostrado na Figura 3.

Figura 3 - Ambiente de ocorrência de CAMBISSOLO HÁPLICO Tb Distrófico na Fazenda Encanto da Natureza na margem direita do rio Teles Pires, imagem panorâmica realizada com drones, altitude de $120 \mathrm{~m}$.

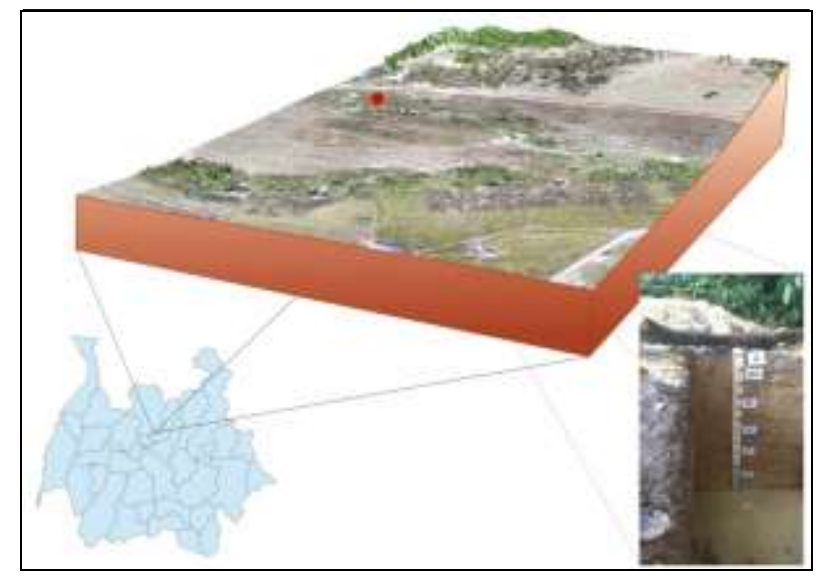

Fonte: Autores.

O CAMBISSOLO HÁPLICO Tb Distrófico encontrado na Fazenda Recanto da Natureza apresenta textura média, cujos atributos químicos mostram que esse solo, em todos os seus horizontes, apresenta baixa fertilidade e caráter distrófico, com alta saturação por alumínio (Tabela 3). De modo geral, esses solos são bastante susceptíveis à erosão, visto que a maior extensão ocorre em relevo ondulado, na área estudada, observou-se relevo suave ondulado, onde as limitações são as presenças 
de pedregosidade e rochosidade. Nestes solos, para o uso de agricultura, deve haver correções de acidez e adubação da área, tendo em vista que as análises apresentaram baixa fertilidade.

Na Fazenda São José, encontra-se o LATOSSOLO VERMELHO-AMARELO Distrófico típico (LVAd), profundo, com boa drenagem e normalmente baixa fertilidade natural, embora se tenham verificado algumas ocorrências de solos eutróficos na região amazônica. Campos et al. (2011) encontraram Latossolo Vermelho-Amarelo Eutrófico, no sul Amazônico, em seus estudos de mineralogia de Latossolos e Argissolos. No entanto, na BHMTP, por ocorrer em relevo plano, o LVAd é utilizado para produção agrícola de soja altamente mecanizada, conforme o bloco diagrama na Figura 4.

Figura 4 - Ambiente de ocorrência de LATOSSOLO VERMELHO-AMARELO Distrófico típico na Fazenda São José na margem direita do rio Teles Pires, imagem panorâmica realizada com drones, altitude de $120 \mathrm{~m}$.

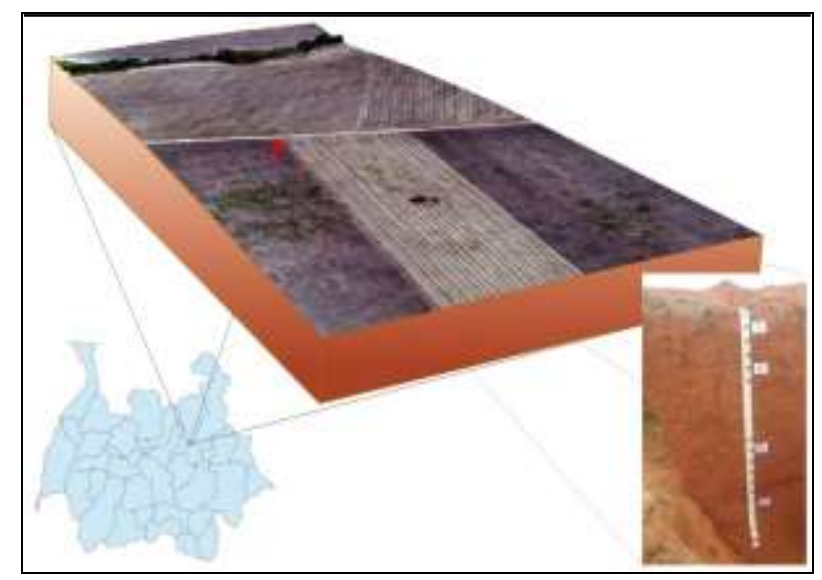

Fonte: Autores.

Os Latossolos são solos bastantes intemperizados, profundos e de boa drenagem. Caracterizam-se por grande homogeneidade de características ao longo do perfil, mineralogia da fração argila predominantemente caulinítica ou caulinítica-oxídica, que se reflete em valores de relação Ki baixos, inferiores a 2,2, e praticamente ausência de minerais primários de fácil intemperização (Santos et al., 2018).

O LATOSSOLO VERMELHO-AMARELO Distrófico típico, da Fazenda São José, apresentou Ds com valores médios e a porosidade total apresentou valores mais altos. As principais limitações que ocorrem nesses solos são as características químicas, pois são solos ácidos, apresentam baixa capacidade de troca de cátions com baixa saturação por bases. As boas condições físicas, aliadas ao relevo plano, favorecem a sua utilização na agricultura. Talvez esse fato explique seu uso voltado para a agricultura intensiva, com alto aporte de capital e tecnologia, o que nem sempre é possível para o pequeno agricultor.

O GLEISSOLO HÁPLICO Tb Distrófico plintossólico (GXbd) (Figura 5) encontra-se na margem esquerda do rio Teles Pires, em relevo plano, com altitude de 243 m, na Depressão Interplanáltica de Alta Floresta, formação geológica Formação Alcalinos do Teles Pires, originados de sedimentos do Holoceno, sob vegetação natural de mata ciliar.

Os Gleissolos são solos característicos de áreas alagadas ou sujeitas a alagamento (margens de rios, ilhas, grandes planícies etc.). Apresentam cores acinzentadas, azuladas ou esverdeadas, dentro de $50 \mathrm{~cm}$ da superfície. Podem ser de alta ou baixa fertilidade natural e têm condições de má drenagem por efeito de flutuação de lençol freático, sob condições de excesso de umidade permanente ou periódico com muita deficiência ou mesmo ausência de oxigênio. Ocorrem em praticamente todas as regiões brasileiras, ocupando principalmente as planícies de inundação de rios e córregos (Santos et al., 2018). 
O GLEISSOLO HÁPLICO Tb Distrófico plintossólico localizado à margem esquerda do rio Teles Pires apresentou textura franco-argiloso, sua limitação decorre da má drenagem e da baixa fertilidade do solo, saturação por base baixa, saturação por alumínio alta. A densidade do solo apresentou valores adequados para a condição de textura média e a porosidade total apresentou valores médios. Nos ambientes Estrada do Espanhol e Comunidade Bonfim ocorrem os ARGISSOLOS VERMELHO-AMARELO Distrófico típico (PVAd), conforme bloco diagramas Figuras 6 e 7.

Figura 5 - Ambiente de ocorrência de GLEISSOLO HÁPLICO Tb Distrófico plintossólico na margem esquerda do rio Teles Pires, imagem panorâmica realizada com drones, altitude de $120 \mathrm{~m}$.

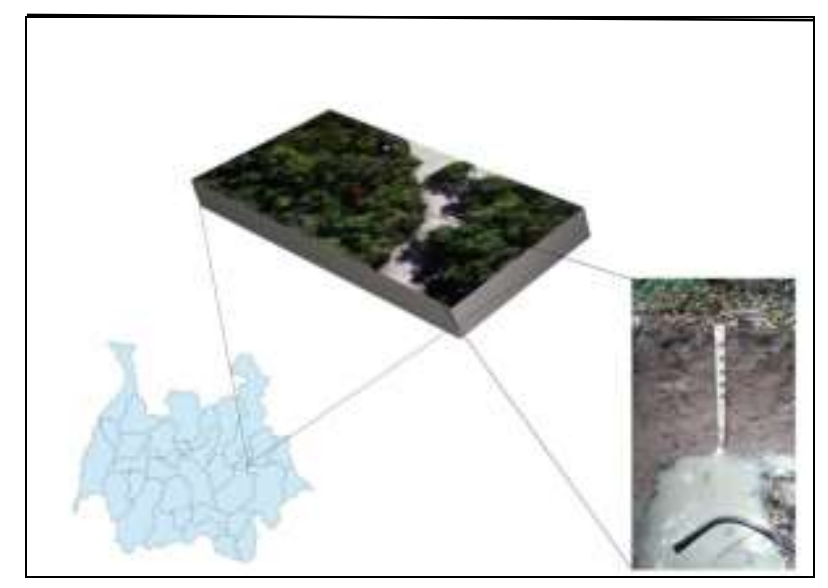

Fonte: Autores.

Os solos dessa classe têm como característica marcante um aumento de argila do horizonte superficial A para o subsuperficial B que é do tipo textural (Bt), geralmente acompanhado de boa diferenciação também de cores e outras características. As cores do horizonte Bt variam de acinzentadas a avermelhadas e as do horizonte A são sempre mais escurecidas. A profundidade dos solos é variável, mas, em geral, são pouco profundos e profundos (Santos et al., 2018).

No ambiente denominado Estrada do Espanhol, verifica-se, na paisagem, a degradação do solo e a exposição de perfis de Argissolo ao longo dos cursos d’água, com retirada de vegetação nativa, juntamente com práticas tradicionais de manejo e pastejo, que favorecem a rápida perda do horizonte arenoso superficial desses solos com ocorrência de voçoroca, deixando o horizonte argiloso rico em nutrientes exposto à superfície.

O ARGISSOLO VERMELHO-AMARELO Distrófico típico da Estrada Espanhol apresenta, em seus horizontes, textura franco-arenosa, argilo-arenosa e franco-argiloso-arenoso, considerado bastante arenoso. A fração argila dispersa em água varia de 20 a $160 \mathrm{~g} \mathrm{~kg}^{-1}$ de solo, evidenciando maior grau de floculação dos coloides nos horizontes superficiais. As características químicas desse solo estão representadas por teores baixos de matéria orgânica, soma de bases trocáveis e capacidade de troca de cátions também muito baixas, com essas características no solo, provoca-se toxidade às plantas cultivadas, exigindo a aplicação de corretivos para eliminação da ação nociva do alumínio.

De modo geral, podem ser utilizados para diversas culturas, desde que sejam feitas correção da acidez e adubação e a adoção de práticas conservacionistas. Nos ambientes adjacentes do perfil estudado, o uso do solo é de pastagem em toda região.

Já o ARGISSOLO VERMELHO-AMARELO Distrófico típico, encontrado na Comunidade Bonfim, apresentou, no ambiente, afloramentos de rochas bem expressivos sobre a paisagem. O relevo se caracteriza como suave a ondulado. O uso do solo nessa região é por pequenos agricultores da agricultura familiar, desenvolvendo atividades como criação de gado leiteiro e 
a produção de hortifruticultura. A utilização da terra também é caracterizada pela criação de gado de corte, sendo a pecuária a principal fonte econômica da região da BHMTP (Figura 7).

Figura 6 - Ambiente de ocorrência de ARGISSOLO VERMELHO-AMARELO Distrófico típico na margem esquerda do rio Teles Pires, Estrada do Espanhol, imagem panorâmica realizada com drones, altitude de $120 \mathrm{~m}$.

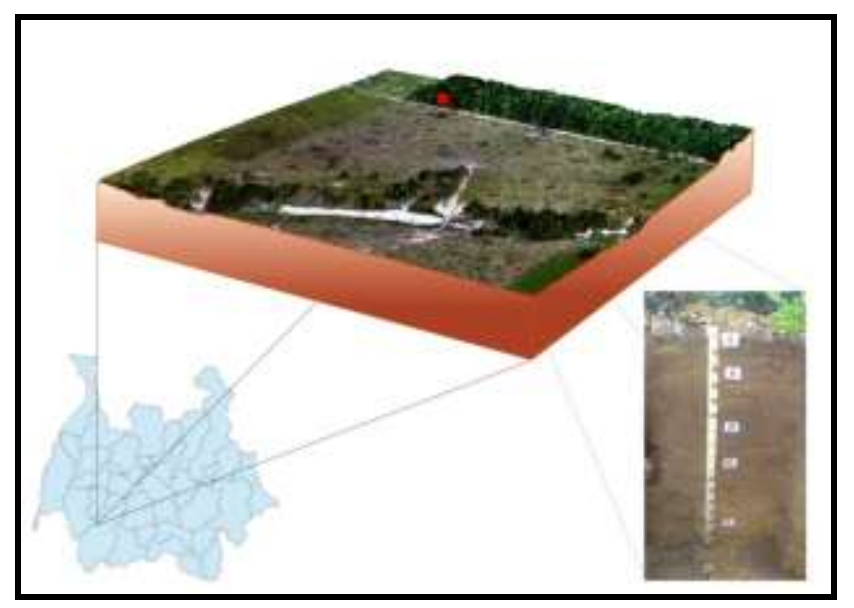

Fonte: Autores.

A limitação desse solo são as características químicas, pois são solos ácidos, com saturação por alumínio alta e baixa saturação por bases. Outro problema enfrentado na área, em função da grande fragilidade à erosão em razão da relação textural impedir, em parte, adequada percolação de água no perfil, e também, por conta do relevo suavemente ondulado, é necessário que sejam implantadas práticas de conservação do solo nesse local.

Figura 7 - Ambiente de ocorrência de ARGISSOLO VERMELHO-AMARELO Distrófico típico na margem esquerda do rio Teles Pires, Comunidade Bonfim, imagem panorâmica realizada com drones, altitude de $120 \mathrm{~m}$.

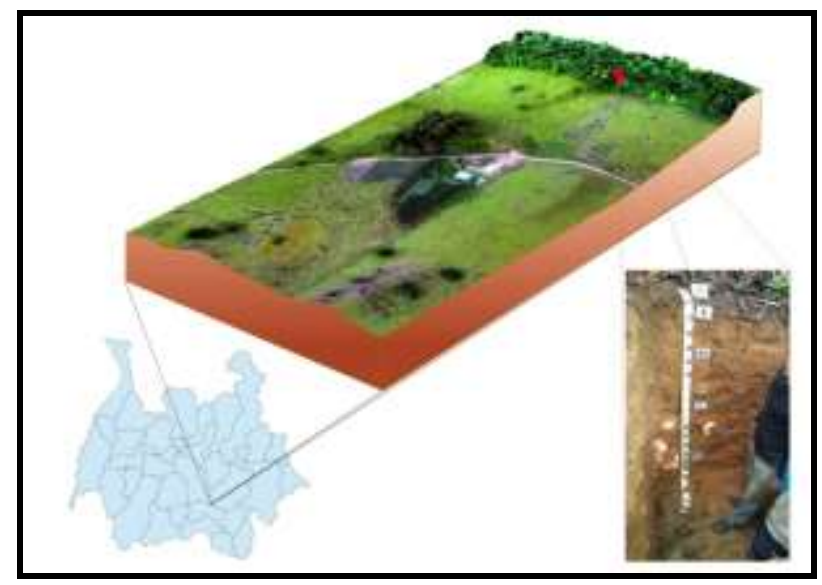

Fonte: Autores.

É importante ressaltar que os Argissolos dessa região podem apresentar grandes variações de espessura em função dos elevados índices pluviométricos, neste caso, o clima e o relevo são fatores predominantes na formação desses solos. No que se refere à ocorrência dos solos no norte de Mato Grosso, são originários de litologias do Complexo Xingu, com predomínio de solos distróficos. 
No ambiente denominado Fazenda Vaca Branca, encontra-se o LATOSSOLO VERMELHO Eutrófico típico (LVe) (Figuras 8), região de floresta nativa, sobre relevo plano. Encontra-se, nessa região, uma área plantada com culturas de soja e milho, permitindo se observar um grau bastante elevado de tecnificação, representado pela quantidade de tratores, colheitadeiras e caminhões na região.

Figura 8 - Ambiente de ocorrência de LATOSSOLO VERMELHO Eutrófico típico na margem direita do rio Teles Pires, Fazenda Vaca Branca, imagem panorâmica realizada com drones, altitude de $120 \mathrm{~m}$.

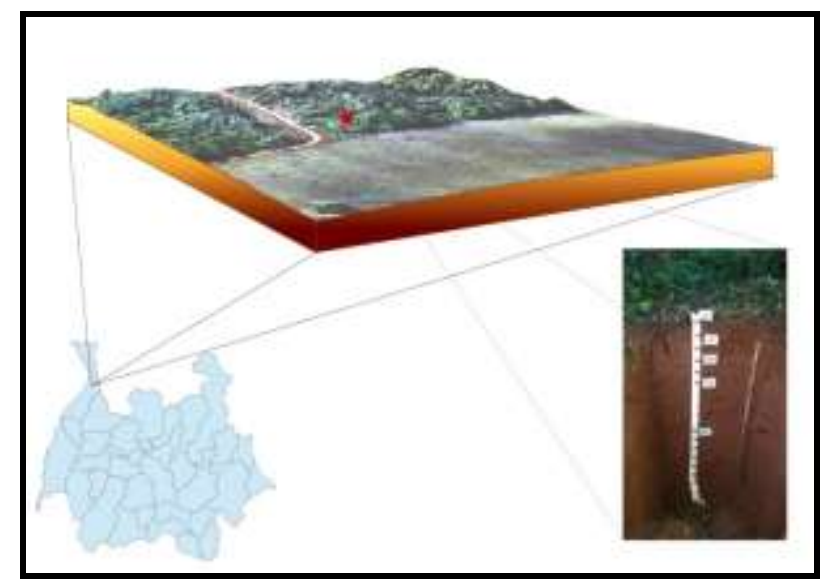

Fonte: Autores.

O LATOSSOLO VERMELHO Eutrófico típico na Fazenda Vaca Branca apresenta classe textural argilo-arenosa e argila e argilosa, bem drenado, possui uma densidade adequada para o tipo de textura e boa porosidade total. Esses solos apresentaram características físicas adequadas, aliadas com o tipo de relevo plano, tornam-se capazes de suportar atividades agrícolas intensivas, o que é verificado na região pela implantação de uma agricultura de soja e milho.

O LATOSSOLO VERMELHO Eutrófico típico nesse trabalho foi o que apresentou melhores características físicas e químicas, portanto, não tendo muita restrição para utilização desse solo com atividades agrícolas.

Vale ressaltar que os LATOSSOLO VERMELHO Eutrófico típico, existem também algumas limitações, há existência de barreiras químicas, como a presença de alumínio que impede o desenvolvimento radicular em profundidade, outra barreira relacionados aos baixos valores da soma de bases e em condições naturais, podem apresentarem baixos níveis de fósforo.

\section{Considerações Finais}

Ainda que haja uma diversidade pedológica na área da Bacia Hidrográfica do Médio Teles Pires (BHMTP), os solos apresentaram características morfológicas, químicas e físicas muito semelhantes.

As características gerais dos solos estudados na BHMTP apresentaram texturas média em todos os perfis. As porcentagens de acidez trocáveis apresentaram-se elevadas na maioria dos horizontes, refletindo os baixos valores de $\mathrm{pH}$ e menores teores de $\mathrm{Ca}, \mathrm{Mg}, \mathrm{K}$ e, consequentemente, menor soma de bases trocáveis.

Em todos os perfis estudados, na Fazenda Recanto da Natureza, Fazenda São José, Rio Teles Pires, Fazenda Estrada do Espanhol e Comunidade Bonfim, apresentaram-se valores baixos de V\%, podendo ser classificados no $3^{\circ}$ nível categórico do Sistema Brasileiro de Classificação de Solos como Distrófico, exceto para a Fazenda Vaca Branca, que apresentou valor alta de V\% em todos os horizontes, atribuindo-se como Eutrófico.

$\mathrm{O}$ uso de geotecnologia com drones no mapeamento e criação de blocos diagramas da distribuição dos solos e paisagem apresenta inúmeras condições para se trabalhar o estudo do meio e socioambiental na BHMTP. Os dados aqui 
apresentados da BHMTP servirão como base de fortalecimento no estudo de geociências com ênfase na interação ciências ambientais $\mathrm{x}$ ciência do solo x geociências na região amazônica.

\section{Referências}

Adhikari, K., \& Hartemink, A. E. (2016). Linking soils to ecosystem services-A global review. Geoderma, 262, $101-111$.

Andrade, H., Schaefer, C.E.; Dematté, J.L. I., \& Andrade, F.V. (1997). Pedogeomorfologia e micropedologia de uma sequência Latossolo - Areia Quartzosa Hidromórficas sobre rochas cristalinas do Estado do Amazonas. Geonomos, 5(1), 55-66.

Barbosa, T. M. B. (2017). Mineralogia e disponibilidade de fósforo em solos de terra firme da Amazônia Central. Manaus: UFAM. Tese (Doutorado em Agronomia Tropical). Universidade Federal do Amazonas.

Barros, G. M. (2013). Caracterização de solos ao longo de uma litossequência no Oeste do Pará, Amazônia Oriental. Recife: UFRPE. Dissertação (Mestrado em Ciência do Solo). Universidade Federal Rural de Pernambuco.

Barros, R., K. Lima, V., H. Canellas, O., L. Kern, C., D. (2012). Fracionamento químico da matéria orgânica e caracterização física de Terra Preta de Índio. Revista de Ciências Agrárias. 55(1). 44-51.

Benedetti, U. G. Vale Júnior, J. F.; Schaefer, C. E. G. R.; Melo, V. F.; \& Uchôa, S. C. P. (2011). Gênese, química e mineralogia de solos derivados de sedimentos pliopleistocênicos e de rochas vulcânicas básicas em Roraima, Norte Amazônico. Revista Brasileira de Ciência do Solo, 35(2), $299-312$.

Bünemann, E. K., Bongiorno, G., Bai, Z., Creamer, R. E., De Deyn, G., de Goede, R., \& Brussaard, L. (2018). Soil quality-A critical review. Soil Biology and Biochemistry, 120, 105-125.

Camargo, M. F., Roque, C. G., Umetsu, R. K., Pierangeli, M. A. P., \& Silva, T. R. C. D. (2010). Fertilidade do solo da área ciliar da sub-bacia hidrográfica Mariana, para fins de conservação ambiental.

Campos, M. C. C. (2012). Relações solo-paisagem: conceitos, evolução e aplicações Soil-landscape relationships: concepts, developments and applications. Ambiência, 8(3), 963-982.

Campos, M. C. C., Ribeiro, M. R., Souza Júnior, V. S. D., Ribeiro Filho, M. R., \& Almeida, M. D. C. D. (2012). Relações solo-superfície geomórfica em uma topossequência várzea-terra firme na região de Humaitá (AM). Revista Brasileira de Ciência do solo, 36, $325-336$.

Campos, M. C. C., Ribeiro, M. R., Souza Júnior, V. S. D., Ribeiro Filho, M. R., \& Souza, R. V. C. C. D. (2011). Relações solo-paisagem em uma topossequência sobre substrato granítico em Santo Antônio do Matupi, Manicoré (AM). Revista Brasileira de Ciência do Solo, 35 , $13-23$.

Campos, M. C. C., Ribeiro, M. R., Souza Júnior, V. S. D., Ribeiro Filho, M. R., \& Oliveira, I. A. D. (2010). Interferências dos pedoambientes nos atributos do solo em uma topossequência de transição Campos/Floresta. Revista Ciência Agronômica, 41, 527-535.

Cardoso, E. L., Santos, S. A., Urbanetz, C., Carvalho, A. D., Naime, U. J., Silva, M. L. N., \& Curi, N. (2016). Relação entre solos e unidades da paisagem no ecossistema Pantanal. Pesquisa Agropecuária Brasileira, 51, 1231-1240.

Cardoso, E. J. B. N., Vasconcellos, R. L. F., Bini, D., Miyauchi, M. Y. H., Santos, C. A. D., Alves, P. R. L., \& Nogueira, M. A. (2013). Soil health: looking for suitable indicators. What should be considered to assess the effects of use and management on soil health?. Scientia Agricola, 70, $274-289$.

Colodel, J. R., Pierangeli, M. A. P., Souza, M. F. P., de Carvalho, M. A. C., \& Dalchiavon, F. C. (2018). Atributos físicos e biológicos de Argissolo VermelhoAmarelo Amazónico sob diferentes sistemas de uso e manejo. Revista de Ciências Agrárias, 41(2), $287-297$.

Costa, E., Silva, H., \& Ribeiro, P. R. (2013). Matéria orgânica do solo e o seu papel na manutenção e produtividade dos sistemas agrícolas. Enciclopédia biosfera, 9(17), 1842-1860.

Damaceno, J. B. D. \& Lobato, A. C. N.(2015). Solos do Amazonas: descrição de um perfil de solo. Revista Delos Desarrollo Local Sostenible, $12(34), 1$-12.

Defelipo, B. V. \& Ribeiro, A. C. (1991). Análise química do solo (metodologia). Viçosa: UFV, 14p. Boletim de Extensão.

Empresa Brasileira De Pesquisa Agropecuária - Embrapa. (2017). Manual de métodos de análises de solo. 3. ed. Revista e Ampliada. Brasília: CNPS. 577 p.

Góis Orrutéa, A., Melo, V. D. F., Motta, A. C. V., \& Lima, V. C. (2012). Mineralogia e reserva de K de Cambissolos submetidos a diferentes manejos após derrubada e queima da floresta na Amazônia Meridional. Acta Amazônica, 42, 461-470.

Kiehl, E. J. (1979). Manual de edafologia. Relações solo-planta [Brasil].

Lange, A., Dantas, J., da Silva Freddi, O., Buratto, W., Spaziani, C., \& Caione, G. (2019). Degradação do solo e pecuária extensiva no norte de Mato Grosso. Nativa, 7(6), 642-648.

Lepsch, I. F. (2016). Formação e conservação dos solos. Oficina de textos.

Lisbôa, F. M., Donagemma, G. K., Burak, D. L., Passos, R. R., \& Mendonça, E. D. S. (2016). Indicadores de qualidade de Latossolo relacionados à degradação de pastagens. Pesquisa agropecuária brasileira, 51, 1184-1193.

Malheiros, A. F., Higuchi, N., \& Santos, J. D. (2009). Structural analysis of tropical rainforest in Alta Floresta city, Mato Grosso, Brazil. Acta Amazonica, 39(3), 539-548. 
Marques, J. D. D. O., Libardi, P. L., Teixeira, W. G., \& Reis, A. M. (2004). Estudo de parâmetros físicos, químicos e hídricos de um Latossolo Amarelo, na região Amazônica. Acta amazônica, 34, 145-154.

Mendes, D. D. S. O., Bueno, G. T., Guimarães, F. S., Rossin, B. G., \& do Nascimento, N. R. (2017). Os solos e geoambientes das campinaranas amazônicas: relação genética entre os geoambientes e a evolução da paisagem em um transecto na bacia do Alto Rio Negro, Amazônia. Revista Brasileira de Geomorfologia, 18(3). 547-559.

Monteiro, K. F. G., Kern, D. C., Rodrigues, T. E., Ruivo, M. D. L. P., \& Farias, P. R. S. (2006). Caracterização dos Argissolos amarelos com adição de resíduos de madeira: uma alternativa de uso como cobertura em solos da Amazônia paraense. Bol. Mus. Para. Emílio Goeldi. Ciências Naturais.1(1), 139-148.

Moreira, M. L. (2007). Mato Grosso: solos e paisagens. Entrelinhas.

Novais, R. D., \& Smyth, T. J. (1999). Fósforo em solo e planta em condições tropicais (No. 631.422 N934). Universidade Federal de Vicosa, Vicosa, MG (Brasil). Dept. de Solos.

Oliveira, A. S. D. (2006). Qualidade do solo em sistemas agroflorestais em Alta Floresta MT. Viçosa: UFV. Dissertação (Mestrado em Solos e Nutrição de Plantas). Universidade Federal de Viçosa.

Oliveira, I. A. D., Campos, M. C. C., Soares, M. D. R., Aquino, R. E. D., Marques Júnior, J., \& Nascimento, E. P. D. (2013). Variabilidade espacial de atributos físicos em um Cambissolo Háplico, sob diferentes usos na região sul do Amazonas. Revista Brasileira de Ciência do Solo, $37,1103-1112$.

Oliveira, A. S.; Cardoso, I. M.; Sá Mendonça, E; Filho, E. F. \& Jucksch, I. (2016.) Avaliação de atributos orgânicos dos solos em ambientes florestais na Amazônia Matogrossense. Revista Espacios| Vol. 37 ( $\left.\mathrm{N}^{\mathrm{o}} 25\right)$.

Oliveira, A. S., Pierangeli, M. A. P., \& de Sousa, J. B. (2019). Características do meio físico da Bacia Hidrográfica do Médio do Rio Teles Pires, no município de Alta Floresta-MT. Revista Equador, 8(3), 159-177.

Pereira, M. G. Anjos, L. H. C. Dos; Pinheiro Junior, C. R.; Pinto, L. A. S. R.; Neto, E. C. S.; \& Fontana, A. (2019). Formação e caracterização de solos. Organizador Leonardo Tullio. - Ponta Grossa, PR: Atena Editora.

Pereira, G. D. S., Locatelli, M., \& Da Silva Filho, E. P. (2018). A atividade humana como fator de substituição da floresta nativa por diferentes tipos de cobertura vegetal influenciando os aspectos de fertilidade do solo na região de Ariquemes, RO. In: Embrapa Rondônia-Artigo em anais de congresso (ALICE).

Quesada, C. A., Paz, C., Oblitas Mendoza, E., Phillips, O. L., Saiz, G., \& Lloyd, J. (2020). Variations in soil chemical and physical properties explain basinwide Amazon forest soil carbon concentrations. Soil, 6(1), 53-88.

Reichert, J. M., Kaiser, D. R., Reinert, D. J., \& Riquelme, U. F. B. (2009). Variação temporal de propriedades físicas do solo e crescimento radicular de feijoeiro em quatro sistemas de manejo. Pesquisa Agropecuária Brasileira, 44, 310-319.

Reis, M.S, Fernandes, A. R., Grimaldi, C., Desjardins, T., \& Grimaldi, M. (2009). Características químicas dos solos de uma topossequência sob pastagem em uma frente pioneira da Amazônia Oriental. Revista de Ciências Agrárias Amazonian Journal of Agricultural and Environmental Sciences, 52(1), 37-47.

Reis, M. S., Fernandes, A. R., Grímaldi, C., Sarrazin, M., \& Grimaldi, M. (2007). Variação da composição granulométrica e orgânica do solo em uma topossequencia da microrregião de Marabá-PA. Boletim do Museu Paraense Emílio Goeldi-Ciências Naturais, 2(3), 33-44.

Resende, M., Curi, N., Rezende, S. D., Corrêa, G. F., \& Ker, J. C. (1997). Pedologia base para distinção de ambientes. rev. ampl. Viçosa: Núcleo de Estudos de Planejamento e Uso da Terra.

Ribeiro, A. C.; Guimarães, P. T. G.; \& Alvarez, V. H. (1999). Recomendações para o uso de corretivos e fertilizantes em Minas Gerais: 5. Aproximação. Comissão de Fertilidade do solo do estado de Minas Gerais.

Salton, J. C., \& Tomazi, M. (2014). Sistema radicular de plantas e qualidade do solo. Embrapa Agropecuária Oeste-Comunicado Técnico (INFOTECA-E).

Santos, H. G., Jacomine, P. K. T., Dos Anjos, L. H. C., De Oliveira, V. A., Lumbreras, J. F., Coelho, M. R., ... \& Cunha, T. J. F. (2018). Sistema brasileiro de classificação de solos. Brasília, DF: Embrapa.

Santos, L. N. S., Passos, R. R., da Silva, L. V. M., de Oliveira, P. P., de Oliveira Garcia, G., \& Cecílio, R. A. (2010). Avaliação de alguns atributos físicos de um Latossolo Vermelho-amarelo sob diferentes coberturas vegetais. Bioscience Journal, 26(6).940-947.

Santos, R., Lemos, R., Santos, H., Ker, J., \& Anjos, L. S. (2015). SH Manual de descrição e coleta de solo no campo. $5^{\text {a }}$ ed. revistada e ampliada Viçosa. Sociedade Brasileira de Ciência do Solo.

Schaefer, C. E. G. R.; Lima, H. N.; Teixeira, W. G.; Vale Júnior, J. F.; Souza, K. W.; Corrêia, G. R.; Mendonça, B. A. F.; Amaral, E. F.; Campos, M. C. C.; \& Ruivo, M. L. P. (2017) Solos da Região Amazônica. In: Curi, N. C., Ker, J. C., Novais, R. F., Vidal-Torrado, P., Schaefer, C. E. G. Pedologia: solos dos biomas brasileiros.

Silva Junior, C. A., Boechat, C. L., \& de CARVALHO, L. A. (2012). Atributos químicos do solo sob conversão de floresta amazônica para diferentes sistemas na região norte do Pará, Brasil. Bioscience Journal, 28(4). 576-572.

Silva Santos, F. (2018). Petrologia das sucessões vulcânicas do Grupo Colíder na região de Guarantã do Norte e a Serra do Cachimbo, Mato Grosso, Brasil. Cuiabá: UFMT, 2018. Dissertação (Programa de Pós-Graduação em Geociências) - Universidade Federal de Mato Grosso, Instituto de Ciências Exatas e da Terra, Cuiabá, 57 p.

Souza, J. O.; Frasca, A. A. S.; \& Oliveira, C. (2003) Programa Levantamentos Geológicos Básicos do Brasil - PLGB. Geologia e recursos minerais da Província Mineral de Alta Floresta. Brasília CPRM-Serviço Geológico do Brasil/DEPAT/DIEDIG. 
Research, Society and Development, v. 10, n. 9, e34210918157, 2021

(CC BY 4.0) | ISSN 2525-3409 | DOI: http://dx.doi.org/10.33448/rsd-v10i9.18157

Souza, A. L. D., \& Souza, D. R. D. (2006). Análise multivariada para estratificação volumétrica de uma floresta ombrófila densa de terra firme, Amazônia Oriental. Revista Árvore, 30, 49-54.

Souza, D. M.; \& Lobato, E. (2004). Cerrado: correção do solo e adubação. 2. ed. Brasília: Embrapa Informação Tecnológica, 416p.

Teixeira, W. G., Kern, D. C., Madari, B. E., Lima, H. N., \& Woods, W. (2009). As terras pretas de índio da Amazônia: sua caracterização e uso deste conhecimento na criação de novas áreas. Manaus: Embrapa Amazônia Ocidental.

Vieira, M. N. F.; Vieira, L. S.; Santos, P. C. T. C. Dos, \& Chaves, R. S. (2000). Levantamento e conservação do solo. 2. ed. Belém: FCAP, Serviço de documentação e informação. 320 p.

Vilar, C. C. \& Vilar, F. C. M. (2013). Comportamento do fósforo em solo e planta. Campo Digital, v. 8, n. 2.

Villar, M. L. P. (2007). Manual de interpretação de análise de plantas e solos e recomendação de adubação. Cuiabá: EMPAER-MT. 182 p. (EMPAER-MT, Série Documentos, 35).

Volf, M. R. (2015). Formas e disponibilidade de potássio nos solos do Vale do Araguaia. Rio Verde: UniRV. Dissertação (Mestrado em Agronomia). Universidade de Rio Verde -GO. 